\title{
Efeito da incorporação de lodo de ETA contendo alto teor de ferro em cerâmica argilosa
}

\section{(Effect of addition of high iron content sludge from water treatment plant on a clay-based ceramic)}

\author{
L. C. C. Paixão ${ }^{1}$, H. N. Yoshimura ${ }^{2}$, D. C. R. Espinosa $a^{1,3}$, J. A. S. Tenorio ${ }^{1,3}$ \\ ${ }^{1}$ Rede Temática em Engenharia de Materiais CETEC-UFOP-UEMG, Praça Tiradentes 20, Ouro Preto, MG 35400-000 \\ ${ }^{2}$ Instituto de Pesquisas Tecnológicas do Estado de S. Paulo S.A. - IPT \\ Av. Prof. Almeida Prado 532, S. Paulo, SP 05508-901 \\ ${ }^{3}$ Escola Politécnica da USP, Av. Prof. Mello Moraes 2463, S. Paulo, SP 05508-900 \\ hnyoshim@ipt.br
}

\begin{abstract}
Resumo
Foram investigados os efeitos da adição de um lodo de estação de tratamento de água nas características físicas e mecânicas de uma cerâmica preparada com massa argilosa (cerâmica vermelha). O lodo "bruto" apresentou partículas grossas e angulares (tamanho médio $\sim 200 \mu \mathrm{m}$ ), elevado teor de ferro $\left(73,0 \% \mathrm{Fe}_{2} \mathrm{O}_{3}\right.$ para $\left.12,6 \% \mathrm{SiO}_{2}, 8,6 \% \mathrm{Al}_{2} \mathrm{O}_{3}, 5,2 \% \mathrm{CaO}\right)$ e predominância de composto com estrutura amorfa. O lodo calcinado a $1000{ }^{\circ} \mathrm{C}$ transformou-se principalmente nas fases hematita e magnetita e as partículas mantiveram a forma original. $\mathrm{O}$ lodo bruto foi adicionado em uma massa cerâmica industrial em frações de 0 (controle), 2,5 e $10 \%$ em peso. Os corpos prensados foram sinterizados a 950,1000 e $1050{ }^{\circ} \mathrm{C}$ em forno elétrico. A adição de lodo causou diminuição da resistência à flexão do corpo seco, devido à redução da retração linear de secagem. A temperatura máxima de sinterização da cerâmica com lodo, para a não ocorrência de retração linear excessiva, foi diminuída para $\sim 1000^{\circ} \mathrm{C}$. Até esta temperatura, a incorporação do lodo pouco afetou a retração linear da cerâmica, mas aumentou a absorção de água e diminuiu a resistência à flexão. Os efeitos deletérios da incorporação do lodo foram associados à formação de microtrincas ao redor das partículas do lodo, que pouco interagiu com a matriz argilosa. A calcinação ou a cominuição do lodo possibilitou aumentar a resistência à flexão, pela diminuição da severidade das microtrincas. Palavras-chave: lodo de ETA, resíduo, reciclagem, cerâmica vermelha, argila, resistência à flexão.
\end{abstract}

\begin{abstract}
The effect of addition of sludge from water treatment plant on the physical and mechanical properties of a structural clay ceramic (red tile) was investigated. Raw sludge presented large and angular particles (average size of $\sim 200 \mu \mathrm{m}$ ) with high iron content $\left(73.0 \% \mathrm{Fe}_{2} \mathrm{O}_{3}\right.$, $12.6 \% \mathrm{SiO}_{2}, 8.6 \% \mathrm{Al}_{2} \mathrm{O}_{3}, 5.2 \% \mathrm{CaO}$ ), and predominantly amorphous structure. After heating at $1000{ }^{\circ} \mathrm{C}$ the sludge presented hematite and magnetite as predominant phases, and the particles remained with original shape. Raw sludge was added to an industrial clay in the fractions of 0 (control sample), 2, 5, and 10 mass\%. Pressed bodies were sintered at 950, 1000, and $1050^{\circ} \mathrm{C}$ in an electric furnace. The sludge addition caused the lowering of flexural strength of dried body because of the decreasing of linear shrinkage of drying. The maximum sintering temperature of samples, in order to avoid over-firing, was reduced to $1000^{\circ} \mathrm{C}$. Up to this temperature, sludge addition did not affect significantly the linear shrinkage of the ceramic, but tend to increase the water absorption and lower the flexural strength. The deleterious effects of sludge addition were associated to the formation of microcracks around the sludge particles. Sludge did not react very much with the clay matrix. Calcining or milling the sludge resulted in an increase of flexural strength, by the lowering of microcrack severity.

Keywords: sludge from water treatment plant, waste, recycling, red tile, clay, flexural strength.
\end{abstract}

\section{INTRODUÇÃO}

Na atualidade, os problemas ligados à poluição e ao descarte de resíduos industriais são de grande importância e preocupam tanto o setor industrial quanto a sociedade como um todo [1]. As estações de tratamento de água (ETAs) geram enormes quantidades de lodo, sendo necessário buscar alternativas para o reaproveitamento deste resíduo de forma a não agredir o meio ambiente. Neste contexto, um setor que apresenta um enorme potencial para contribuir na solução de problemas ambientais originários nos mais diversos processos industriais é o da cerâmica vermelha. De fato, trabalhos reportados na literatura têm mostrado que é possível a reciclagem de resíduos industriais como constituintes de massas cerâmicas para a fabricação de produtos para a construção civil. Exemplos destes resíduos são: lama de sulfato de bário proveniente de indústria de processamento de celulose e papel [2]; borra de petróleo [3]; lama galvânica gerada por indústria de galvanoplastia [4]; lodo 
da estação de tratamento de efluente de indústria de revestimento cerâmico [5]; pó de aciaria [6]; lama industrial [7]; e resíduo sólido proveniente do setor siderúrgico [1]. A reutilização destes resíduos pode resolver, de um lado, o problema de descarte em área da estação de tratamento e, por outro lado, diminuir a quantidade de massa argilosa consumida e, portanto, o custo da matéria-prima para produção da cerâmica. Também, pode diminuir as atividades extrativas de argila, que em muitos casos causa danos ambientais por, em geral, não envolver projetos de recuperação de áreas por parte das empresas de blocos cerâmicos.

As estações de tratamento de água captam água de rios, realizam tratamento e a distribuem sob a forma de água potável aos centros de consumo humano. Os processos utilizados nestas estações consistem em geral de: oxidação; coagulação; floculação; decantação; filtração; desinfecção; estabilização do $\mathrm{pH}$; e fluoretação. $\mathrm{Na}$ oxidação é injetado cloro na água bruta captada para oxidar os metais presentes dissolvidos, principalmente, o ferro e o manganês. Na coagulação adicionase cal e, logo após, sais de alumínio ou sais de ferro como coagulante primário para formar flocos de impurezas. $\mathrm{Na}$ floculação, a água é misturada em tanques para formação de flocos de impurezas maiores para o início da fase de decantação. Após a decantação, a água passa por filtros com antracito, areia e cascalho, retendo as impurezas que não foram sedimentadas nas etapas anteriores. As impurezas retiradas da água originárias, principalmente, dos decantadores e das águas de lavagem dos filtros são denominadas de lodo de estação de tratamento de água - lodo de ETA. As características dessas impurezas dependem das condições da água bruta retirada do manancial, dosagens e produtos químicos utilizados e a forma de limpeza dos filtros dos decantadores [8-10].

Devido à adição de sais de alumínio ou sais de ferro para provocar a coagulação dos resíduos existentes na água bruta, os hidróxidos desses sais passam a ser os principais componentes químicos do lodo e, além disso, partículas orgânicas e inorgânicas. Na ausência de algas e outros materiais orgânicos no manancial, a fração orgânica do lodo torna-se desprezível e o lodo passa a ter características de estabilidade química, sendo composto principalmente de areias finas, limos e argilas [8,9]. As análises químicas de metais presentes na fase sólida de lodo em três estações de tratamento de água do estado de São Paulo mostraram grande variação de composição química entre os diferentes lodos; foram observados elevados teores de alumínio, ferro total, sódio e cálcio, sendo que as concentrações de ferro e alumínio dependem do tipo de coagulante utilizado durante a fase de tratamento da água denominada floculação [9].

Alguns estudos verificaram a influência da incorporação do lodo de ETA em massa cerâmica a base de argila. Em um estudo foram adicionados $2 \%$ de lodo gerado nos decantadores da ETA de São Leopoldo, RS, rico em $\mathrm{SiO}_{2}, \mathrm{Al}_{2} \mathrm{O}_{3}$ e $\mathrm{Fe}_{2} \mathrm{O}_{3}$, em duas argilas industriais e a adição de lodo pouco influenciou as características físicas e mecânicas de blocos cerâmicos [11]. Em outro estudo, a adição de 5 a 20\% deste mesmo lodo, em uma argila, causou a diminuição da absorção de água e da resistência à flexão com o aumento da fração de lodo [12]. Os autores não apresentaram explicação para o efeito deletério da adição de lodo na resistência mecânica da cerâmica. Em outro trabalho, a adição de um lodo de ETA, de uma indústria petroquímica, em uma argila, também causou diminuição significativa da resistência à flexão, além de ter aumentado a absorção de água e a porosidade aparente com o aumento da fração de lodo incorporado, tendo sido os efeitos deletérios associados ao comportamento nãoplástico do lodo [13]. A fração máxima de adição de lodo para uso em cerâmica vermelha indicada variou entre 10 e $20 \%$, dependendo da temperatura de queima (sinterização) e a forma de prensagem (manual ou mecânica) [13]. Neste trabalho, entretanto, as características físicas e químicas do lodo utilizado não foram apresentadas.

Há outros trabalhos mostrando que a resistência mecânica de cerâmica argilosa diminui com o aumento da fração de resíduo incorporada $[3,6,7]$, mas nenhum destes trabalhos apresenta explicação para este enfraquecimento. Geralmente, os resíduos são apenas parcialmente caracterizados e as análises microestrutural e fractográfica não são realizadas, o que dificulta identificar as causas do efeito deletério dos resíduos nas propriedades mecânicas das cerâmicas. Exceção é o trabalho de Souza e Holanda [14], no qual identificaram que a causa da diminuição da resistência à compressão com o aumento da fração de resíduo borra de petróleo foi a presença de materiais não plásticos (quartzo e barita), cujas partículas estavam fracamente ligadas à matriz sinterizada. Postularam que a diferença entre os coeficientes de expansão térmica entre as partículas do resíduo e a matriz argilosa causou a formação de trincas, que atuaram como sítios de iniciação da fratura e diminuíram a resistência mecânica [14]. Este resultado indica que o tamanho e a distribuição das partículas do resíduo podem afetar significativamente a resistência mecânica das cerâmicas.

O objetivo deste trabalho foi verificar os efeitos da adição de um lodo de ETA nas características físicas de uma massa de cerâmica vermelha, tendo como ênfase a correlação entre as características físicas e químicas do lodo e a resistência à flexão da cerâmica. Também, foram verificados os efeitos do beneficiamento do lodo por meio de calcinação e moagem, visando aumentar a resistência mecânica da cerâmica.

\section{MATERIAIS E MÉTODOS}

As matérias-primas empregadas foram: a) lodo proveniente da ETA do Sistema Rio Manso/COPASA (Companhia de Saneamento de Minas Gerais), localizada no município de Brumadinho - MG, que é tratado com cloreto de ferro, hidróxido de alumínio ou sulfato de alumínio, como elemento coagulante na fase de tratamento de água, dependendo da disponibilidade no mercado; e, b) massa argilosa industrial constituída de mistura de argilas (Unicer), proveniente da região de Santa Gertrudes, SP, normalmente utilizada para fabricação de tijolos e pisos cerâmicos (a escolha desta massa teve como propósito a utilização de um material com constância nas propriedades). A Tabela I apresenta a composição química da massa argilosa, que apresentou na análise de difração de raios X (DRX) as seguintes fases cristalinas [15]: óxido de silício (quartzo alfa); mineral do grupo das micas (provavelmente muscovita); mineral do grupo dos feldspatos (provavelmente anortita); mineral do grupo das 
Tabela I - Composição química da massa argilosa [15]. [Table I - Chemical composition of clay [15].]

\begin{tabular}{cc}
\hline Componente & Teor $(\%)$ \\
\hline Perda ao fogo & $3,2 \pm 0,1$ \\
$\mathrm{SiO}_{2}$ & $69,5 \pm 0,6$ \\
$\mathrm{Al}_{2} \mathrm{O}_{3}$ & $13,5 \pm 0,1$ \\
$\mathrm{Fe}_{2} \mathrm{O}_{3}$ & $5,3 \pm 0,1$ \\
$\mathrm{~K}_{2} \mathrm{O}$ & $3,3 \pm 0,1$ \\
$\mathrm{TiO}_{2}$ & $0,60 \pm 0,01$ \\
$\mathrm{MgO}$ & $2,2 \pm 0,1$ \\
$\mathrm{Na} \mathrm{O}_{2}$ & $1,5 \pm 0,1$ \\
$\mathrm{CaO}$ & $0,64 \pm 0,01$ \\
$\mathrm{MnO}_{2}$ & $0,06 \pm 0,01$ \\
\hline
\end{tabular}

esmectitas (provavelmente montmorillonita); óxido de ferro III (Hematita); e, possivelmente, mineral do grupo da caulinita.

O lodo recebido foi seco a $110{ }^{\circ} \mathrm{C}$ por $48 \mathrm{~h}$ e, então, desaglomerado em moinho de bolas por $20 \mathrm{~min}$. Na primeira série experimental, o lodo foi adicionado em frações de 2,5 e $10 \%$, em peso, à massa argilosa e a mistura foi homogeneizada manualmente, a seco, por $20 \mathrm{~min}$. Em seguida, adicionou-se $10 \%$ de água à mistura, que foi então passada em uma peneira de abertura de $840 \mu \mathrm{m}$ para desaglomerar os grumos de partículas. Por fim, a mistura foi novamente homogeneizada por $20 \mathrm{~min}$. O pó da amostra de controle ( $0 \%$ de lodo) foi preparado seguindo o mesmo procedimento.

A rota de processamento cerâmico empregada seguiu a metodologia de "ensaio preliminar de argila" proposta por Souza Santos [16]. Os corpos-de-prova, com dimensões de $\sim 5,5 \mathrm{x}$ $20,5 \times 61,1 \mathrm{~mm}^{3}$, foram confeccionados por prensagem uniaxial com pressão de compactação de $19,7 \mathrm{MPa}$ em um molde de aço, utilizando uma massa fixa de $15 \mathrm{~g}$ de mistura por corpode-prova. Os corpos prensados foram secos em estufa a $110^{\circ} \mathrm{C}$ por $24 \mathrm{~h}$. A sinterização foi realizada em um forno elétrico a 950 ,
1000 e $1050{ }^{\circ} \mathrm{C}$ por $3 \mathrm{~h}$, com taxa de aquecimento de $5{ }^{\circ} \mathrm{C} / \mathrm{min}$. Dez corpos-de-prova foram preparados e ensaiados em cada condição experimental.

$\mathrm{Na}$ segunda etapa experimental, com o intuito de aumentar a resistência à flexão, uma parte do lodo foi calcinada a $1000^{\circ} \mathrm{C}$ por $3 \mathrm{~h}$ e a outra parte foi moída até a granulometria $100 \%$ passante na peneira de abertura $75 \mu \mathrm{m}$. Estes pós de lodo beneficiados foram incorporados na fração de 5\%, em peso, na massa argilosa, seguindo o mesmo procedimento descrito anteriormente para a adição do lodo "bruto".

O lodo de ETA foi caracterizado por análise granulométrica por peneiramento, análise química por fluorescência de raios $\mathrm{X}$ (FRX), análise por difração de raios X (DRX), microscopia eletrônica de varredura (MEV) e microanálise química por espectroscopia por dispersão de energia (EDS) acoplada ao MEV. Os corpos cerâmicos foram caracterizados por meio de determinação da retração linear, resistência à flexão em três pontos, absorção de água, porosidade aparente e massa específica aparente seguindo os procedimentos usuais (ABNT NBR 6113, 6220 e 6225). As superfícies dos corpos sinterizados e as superfícies de fratura foram analisadas em um estereomicroscópio óptico (EMO). As barras de erro apresentadas nos gráficos representam a incerteza calculada pelo método "t de Student" com grau de confiança de 95\% para dez repetições.

\section{RESULTADOS E DISCUSSÃO}

\section{Lodo de ETA}

AFig. 1 apresenta os resultados da análise granulométrica. O lodo de ETA apresentou distribuição bi-modal de tamanho de partículas, com um valor modal de partículas grossas de $250 \mu \mathrm{m}$ e um segundo valor modal de partículas finas ao redor de $45 \mu \mathrm{m}$ (Fig. 1a). O tamanho de partícula médio $\left(D_{50}\right)$ e o tamanho em $90 \%$ da curva acumulada $\left(D_{90}\right)$ foram
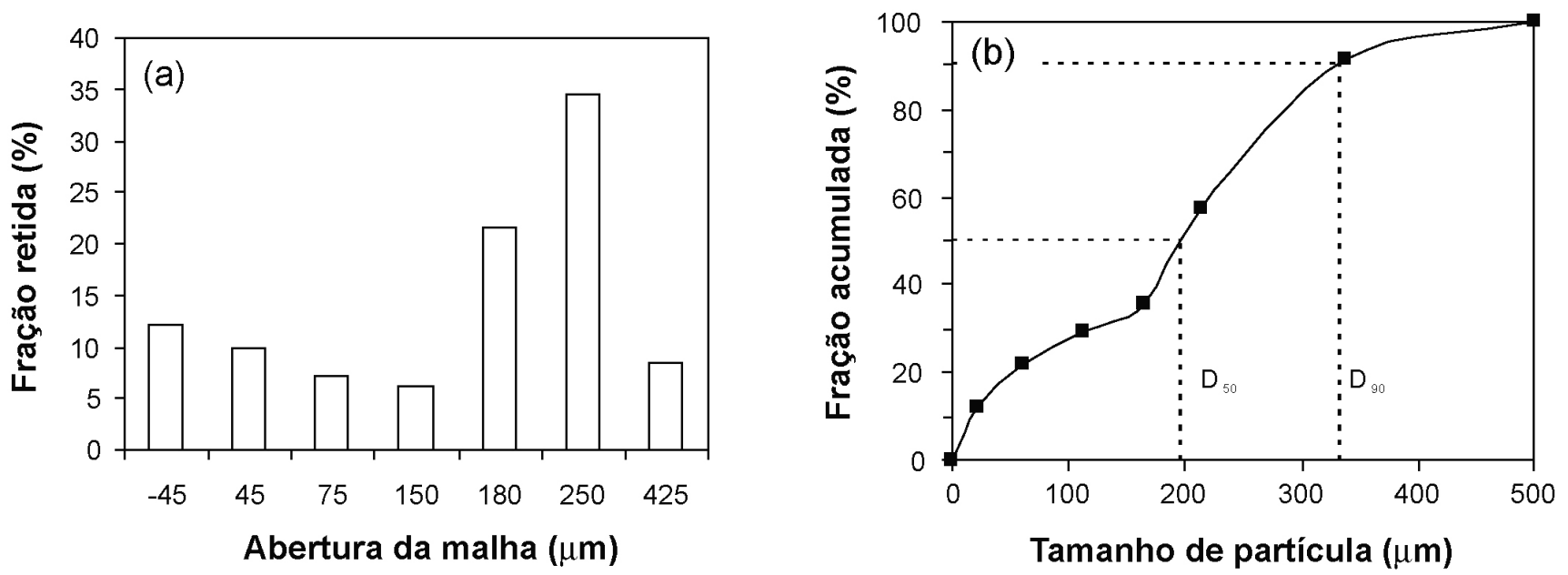

Figura 1: Resultados da análise granulométrica em função da fração retida (a) e fração acumulada (b). Em (a), a fração retida em -45 $\mu$ m é a fração passante na malha de $45 \mu \mathrm{m}$, que fica retida no fundo do recipiente.

[Figure 1: Results of particle size analysis as a function of retained fraction (a) and cumulative fraction (b). In (a), the retained fraction at $-45 \mu \mathrm{m}$ is the fraction of particles smaller than $45 \mu \mathrm{m}$, retained in the bottom of recipient.] 
de 198 e $334 \mu \mathrm{m}$, respectivamente (Fig. 1b).

A Fig. 2 apresenta imagens de MEV do lodo, mostrando que as partículas apresentaram formas angulares com superfícies relativamente lisas (facetadas) e, algumas, com forma de plaquetas (Fig. 2a). Partículas finas com tamanhos de alguns micrometros foram observadas nas superfícies das partículas facetadas (Fig. 2b). As microanálises químicas por EDS realizadas nas partículas finas depositadas sobre as partículas facetadas (Fig. 3a) apresentaram elevados teores de $\mathrm{O}, \mathrm{Fe}, \mathrm{Si}$ e $\mathrm{Ca}$, além de pequenas proporções de $\mathrm{K}$, Ti, Al e Mg (Figs. 3b e 3c). Já, as superfícies das partículas facetadas apresentaram elevado teor de Fe, seguido de $\mathrm{Si}$ e $\mathrm{O}$ e pequenas proporções de $\mathrm{Ca}$, Ti e $\mathrm{Al}$ (Fig. 3d).

A Fig. 4 apresenta o padrão de DRX do lodo bruto. Observou-se uma larga banda ao redor de $10^{\circ}$ de ângulo

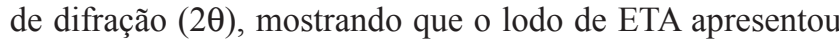
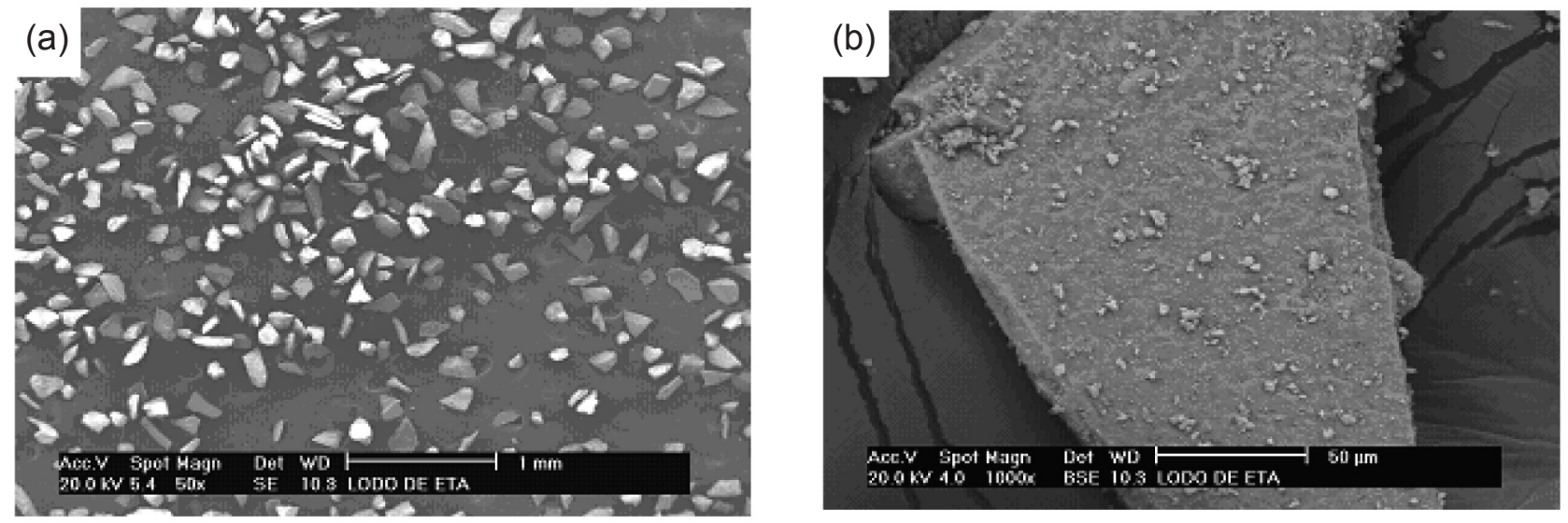

Figura 2: Imagens de MEV das partículas do lodo bruto: (a) imagem de pequena ampliação do pó; e, (b) detalhe de uma partícula facetada. [Figure 2: SEM images of particles of raw sludge: (a) low magnification image of the powder; and (b) detail of a faceted particle.]

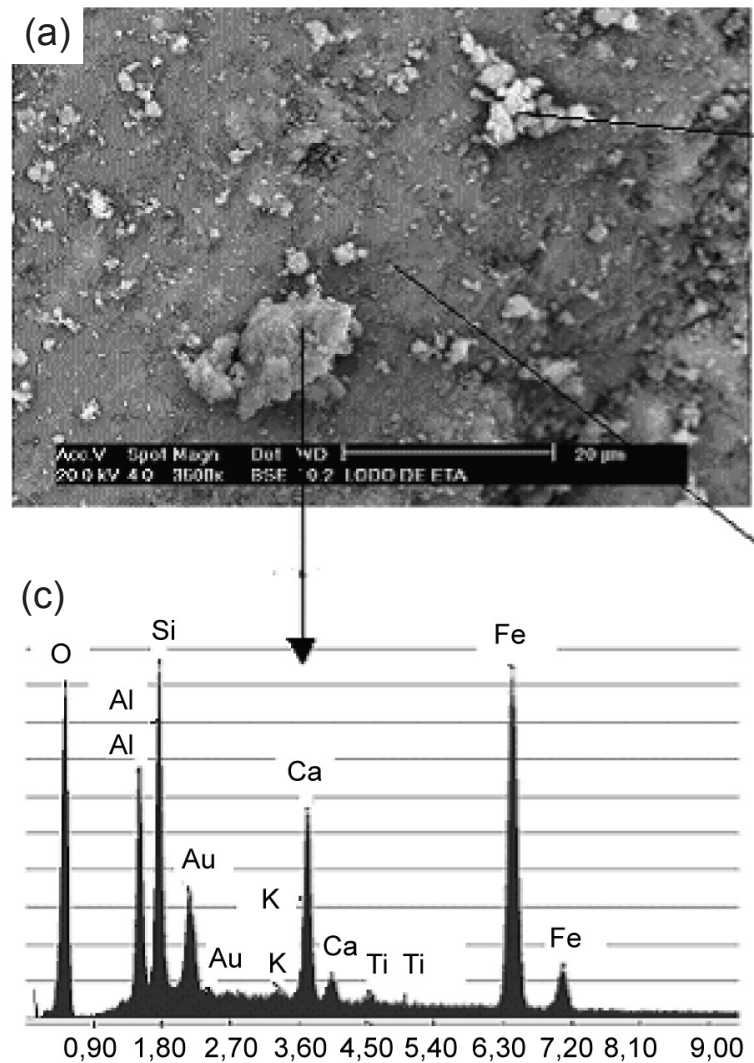

(b)
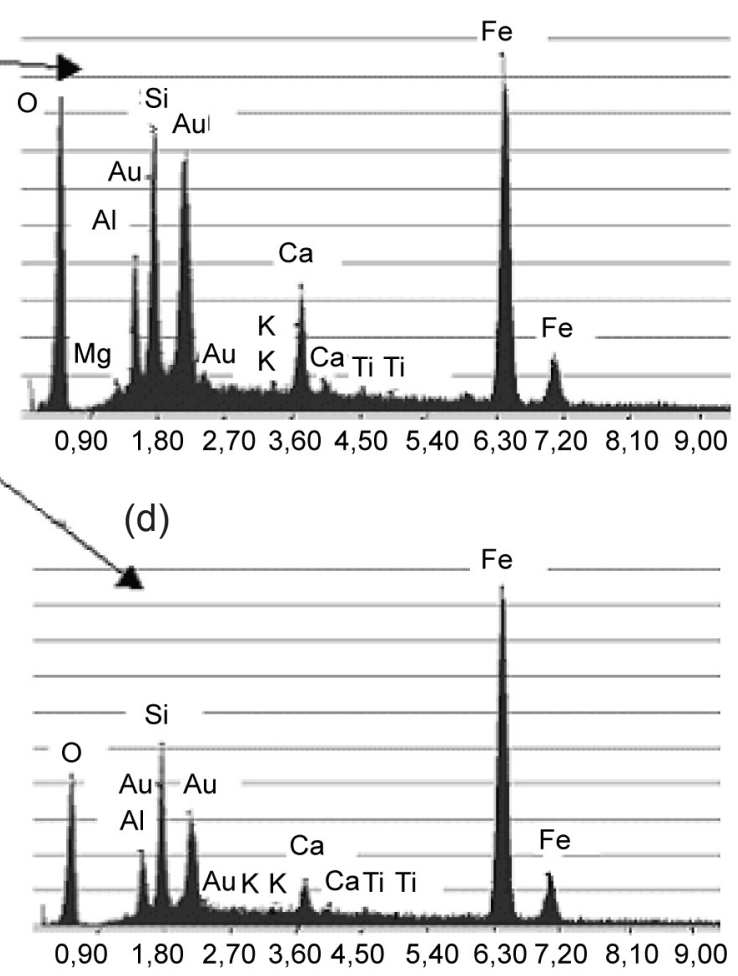

Figura 3: Imagem de MEV de partículas finas sobre partícula facetada grande no lodo bruto e espectros de EDS das regiões indicadas. [Figure 3: SEM image of fine particles over a large planar particle in raw sludge and EDS results from indicated areas.] 


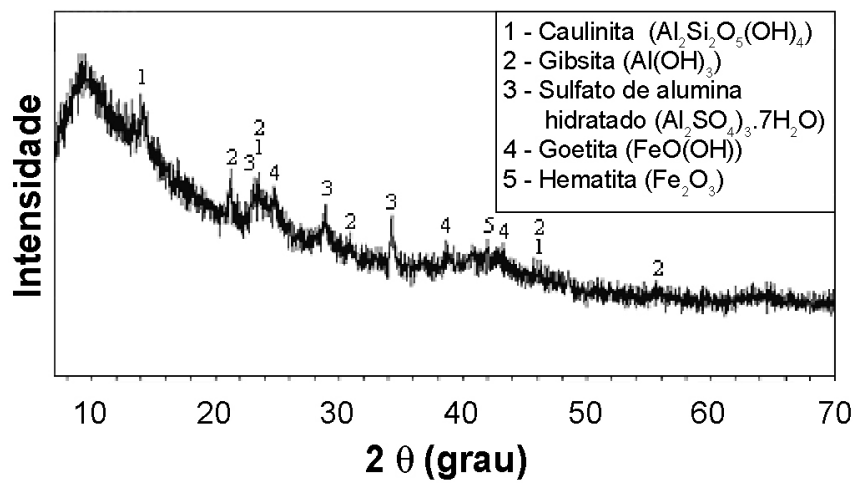

Figura 4: Difratograma de raios $X$ do lodo bruto.

[Figure 4: X-ray diffraction pattern of raw sludge.]

predominância de fase amorfa. As fases cristalinas identificadas foram caulinita $\left(\mathrm{Al}_{2} \mathrm{Si}_{2} \mathrm{O}_{5}(\mathrm{OH})_{4}\right)$, gipsita $\left(\mathrm{Al}(\mathrm{OH})_{3}\right)$, sulfato de alumínio hidratado $\left(\mathrm{Al}_{2}\left(\mathrm{SO}_{4}\right)_{3} \cdot 7 \mathrm{H}_{2} \mathrm{O}\right)$, goetita $(\mathrm{FeO}(\mathrm{OH}))$ e hematita $\left(\mathrm{Fe}_{2} \mathrm{O}_{3}\right)$.

A Tabela II apresenta os resultados da análise química do lodo. Observou-se que o lodo foi composto, predominantemente, por óxido de ferro $\left(73,0 \% \mathrm{Fe}_{2} \mathrm{O}_{3}\right)$, seguido de $\mathrm{SiO}_{2}(12,6 \%), \mathrm{Al}_{2} \mathrm{O}_{3}(8,6 \%)$ e $\mathrm{CaO}(5,2 \%)$, com teores menores que $1 \%$ de $\mathrm{MnO}$ e $\mathrm{CuO}$. Os resultados dos

Tabela II - Resultados da análise química do lodo de ETA. [Table II - Results of chemical analysis of sludge from water treatment plant.]

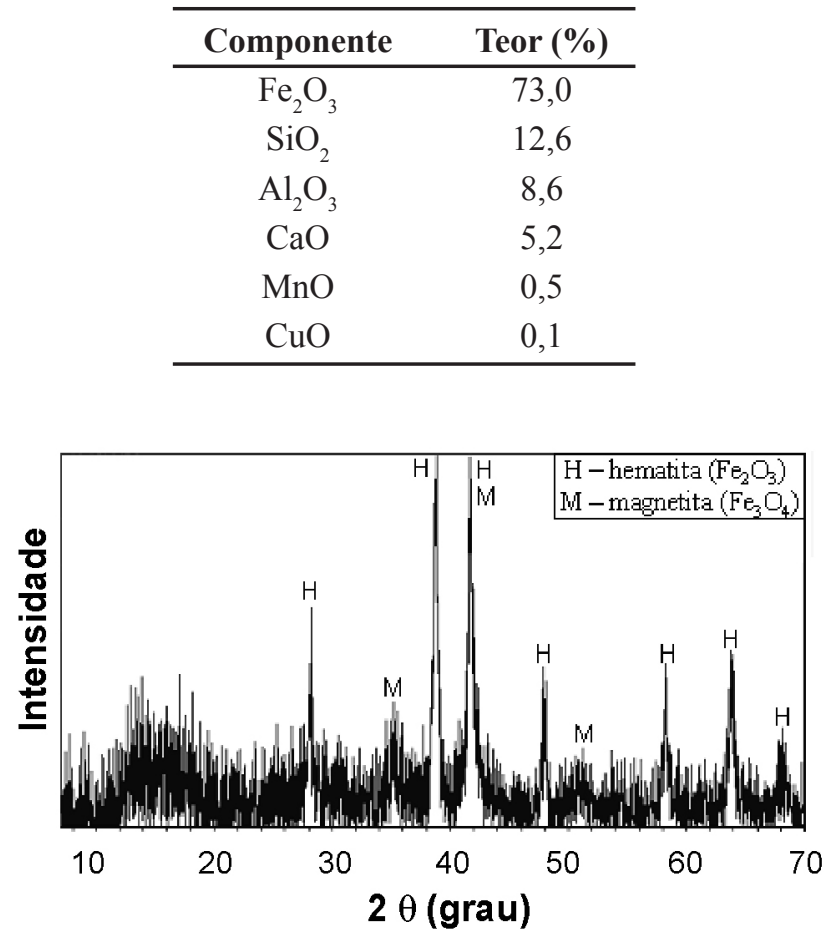

Figura 5: Difratograma de raios $\mathrm{X}$ do lodo calcinado a $1000{ }^{\circ} \mathrm{C}$ por $3 \mathrm{~h}$.

[Figure 5: X-ray diffraction pattern of sludge calcined at $1000{ }^{\circ} \mathrm{C}$ for 3 h.] óxidos majoritários foram coerentes com os resultados de EDS das partículas do lodo (Fig. 3), mas houve diferenças nos resultados dos óxidos minoritários. O elevado teor de óxido de ferro possivelmente foi decorrente do uso de cloreto de ferro como elemento coagulante na fase de tratamento de água da ETA e indicou que a fase amorfa constatada no padrão de DRX do lodo bruto (Fig. 4) foi um composto rico em Fe. Corrobora esta assertiva o resultado da análise de DRX do lodo calcinado, cujo padrão de difração (Fig. 5) apresentou predominância de fase hematita $\left(\mathrm{Fe}_{2} \mathrm{O}_{3}\right)$ com pequena fração de fase magnetita $\left(\mathrm{Fe}_{3} \mathrm{O}_{4}\right)$.

Os resultados das análises de DRX (Figs. 4 e 5) mostraram que houve alteração da estrutura cristalina do lodo quando submetido a um tratamento térmico a altas temperaturas. $\mathrm{O}$ tratamento de calcinação a $1000{ }^{\circ} \mathrm{C}$, entretanto, não causou mudança significativa na morfologia das partículas, não tendo sido observado qualquer indício de fusão parcial do lodo (Fig. 6). Devido à reduzida quantidade de amostra, não foi realizada a análise granulométrica do lodo calcinado, mas a perda de massa na calcinação de $18 \%$ sugere que as partículas apresentaram certo grau de retração. Considerando que a decomposição térmica ao ar de compostos amorfos resulta nos respectivos óxidos cristalinos com maiores valores de densidade e que não ocorreu mudança de morfologia e nem formação de poros nas superfícies das partículas (Fig. 6), pode-se inferir que ocorreu retração das dimensões das partículas do lodo durante a calcinação. As microanálises químicas por EDS realizadas nas partículas do lodo calcinado (Fig. 7) mostraram resultados similares aos observados no lodo bruto (Fig. 3), com a diferença de que a intensidade do pico de Fe aumentou tanto nas partículas facetadas como nas partículas finas.

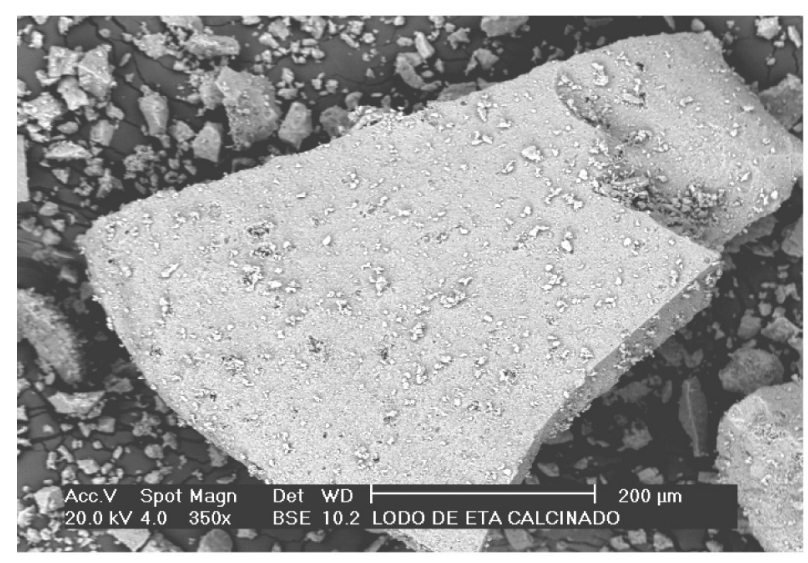

Figura 6: Imagem de MEV do lodo calcinado.

[Figure 6: SEM image of calcined sludge.]

A composição química do lodo de ETA investigado (Tabela II) foi significativamente diferente da composição do lodo de ETA de São Leopoldo, que apresentou 24,3\% de perda ao fogo, $37,9 \%$ de $\mathrm{SiO}_{2}, 22,2 \%$ de $\mathrm{Al}_{2} \mathrm{O}_{3}, 11,1 \%$ de $\mathrm{Fe}_{2} \mathrm{O}_{3} \mathrm{e}<5 \%$ de $\mathrm{P}_{2} \mathrm{O}_{5}, \mathrm{MgO}, \mathrm{TiO}_{2}, \mathrm{Na}_{2} \mathrm{O}, \mathrm{K}_{2} \mathrm{O}, \mathrm{CaO}$ e $\mathrm{MnO}$ [11]. As diferenças nos teores de $\mathrm{Al}_{2} \mathrm{O}_{3}$ e $\mathrm{Fe}_{2} \mathrm{O}_{3}$ confirmam 
(a)
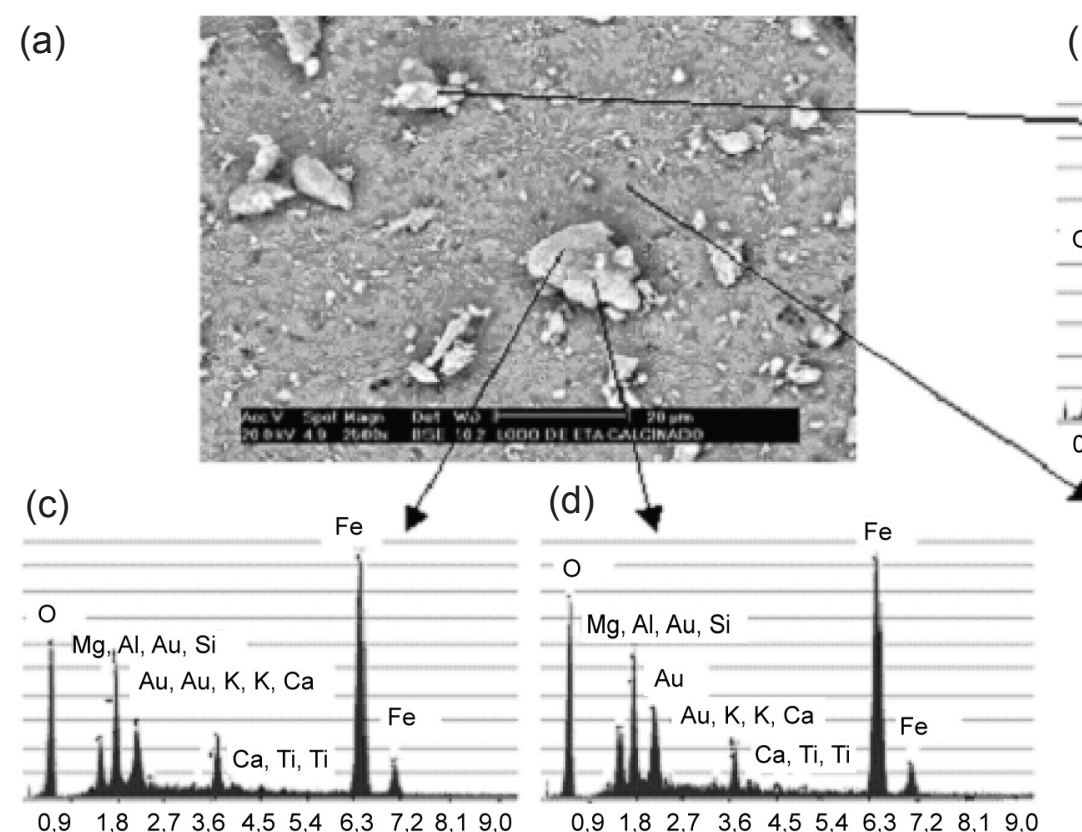

(b)
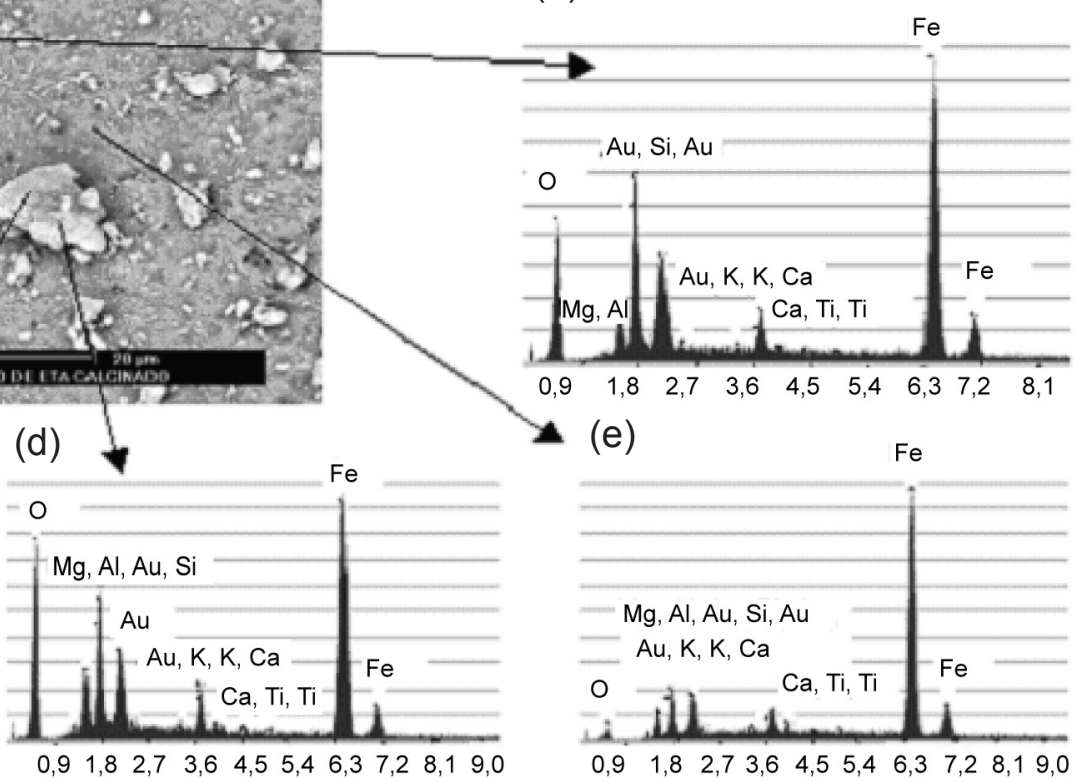

Figura 7: Imagem de MEV de partículas finas sobre partícula facetada grande no lodo calcinado e espectros de EDS das regiões indicadas. [Figure 7: SEM image of fine particles over a large planar particle in the calcined sludge and EDS results from indicated areas.]

que as concentrações de ferro e alumínio variam com o tipo de coagulante utilizado durante a floculação [9]. A diferença no teor de $\mathrm{SiO}_{2}$ pode estar relacionada à fração de matéria inorgânica, tais como areia fina e argila [8,9].

\section{Corpos cerâmicos: efeito da fração de lodo}

A Fig. 8 apresenta os resultados de retração linear e resistência à flexão dos corpos prensados e secos a $110^{\circ} \mathrm{C}$. $\mathrm{A}$ adição do lodo de ETA resultou na diminuição de $\sim 30 \%$ da retração linear em relação ao material de controle (sem lodo), mostrando que as partículas de lodo restringiram a retração da massa argilosa durante a secagem. Os resultados de retração linear das amostras com incorporação de lodo foram iguais, não tendo sido observado efeito da fração de lodo entre 2 e $10 \%$ (Fig. 8). As amostras com 2 e 5\% de lodo apresentaram $\sim 35 \%$ de redução da resistência à flexão em relação ao material de controle. Esta redução foi próxima à observada na retração linear, indicando que a resistência à flexão do corpo seco foi principalmente definida pela retração linear do corpo. A retração causa um empacotamento mais denso de partículas, resultando em maior força de interação entre as partículas, o que aumenta a resistência mecânica do corpo. A amostra com $10 \%$ de resíduo, entretanto, apresentou redução de $\sim 50 \%$ de resistência à flexão em relação à amostra de controle (Fig. 8). Neste caso, outro efeito deletério relacionado à adição de altas frações de lodo parece ter atuado conjuntamente. A redução das propriedades mecânicas dos corpos secos tende a dificultar o manuseio e o transporte do produto conformado, aumentando as perdas por quebras no processo. Tende, também, a introduzir mais defeitos, como microtrincas, durante o processo, que pode aumentar a variabilidade da resistência mecânica dos produtos sinterizados (diminuição do módulo de Weibull). No caso deste trabalho (Fig. 8), um máximo de $\sim 5 \%$ de lodo de ETA é recomendável para o não enfraquecimento excessivo do corpo cerâmico seco.

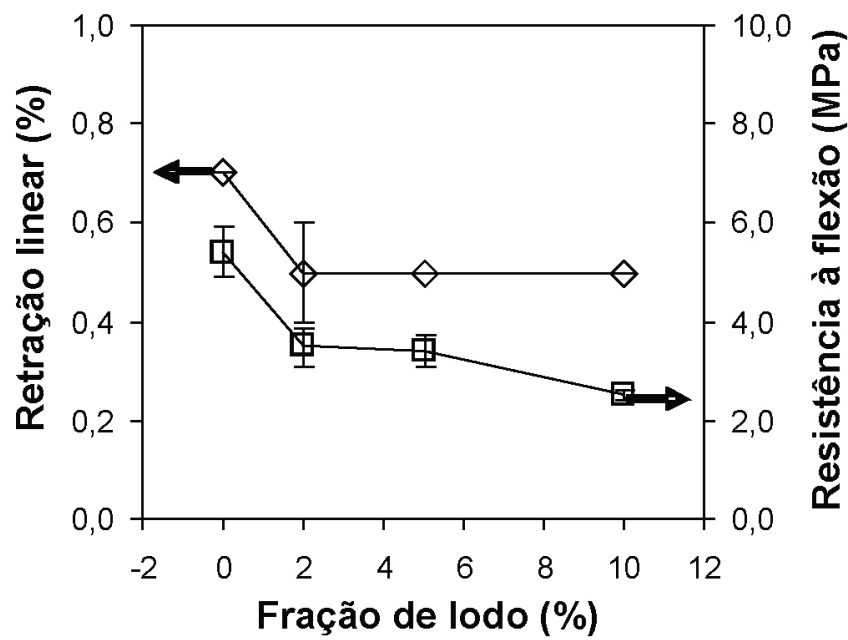

Figura 8: Retração linear e resistência à flexão dos corpos prensados e secos a $110^{\circ} \mathrm{C}$ em função da fração.

[Figure 8: Linear shrinkage and flexural strength of pressed bodies dried at $110^{\circ} \mathrm{C}$ as a function of sludge fraction.]

A Fig. 9 apresenta os resultados das caracterizações físicas das amostras sinterizadas entre 950 e $1050{ }^{\circ} \mathrm{C}$. A adição de lodo pouco afetou a retração linear da massa cerâmica até a temperatura de sinterização de $1000^{\circ} \mathrm{C}$, mas 
aumentou significativamente a $1050{ }^{\circ} \mathrm{C}$ (Fig. 9a). Nesta temperatura, a retração das amostras com lodo foi de $\sim 17 \%$, enquanto a da amostra de controle (sem lodo) foi de $9 \%$. A retração linear excessiva dificulta a obtenção de produtos com boa planicidade e estreitas tolerâncias dimensionais. Tecnologicamente, o valor máximo recomendado para tijolos de boa qualidade é $8 \%$ [7]. A adição do lodo, portanto, diminuiu a temperatura máxima que a massa cerâmica pode ser sinterizada, para que não ocorram distorções excessivas no corpo.

$\mathrm{O}$ rápido aumento da retração linear com o aumento da temperatura de sinterização das amostras com lodo (Fig. 9a)
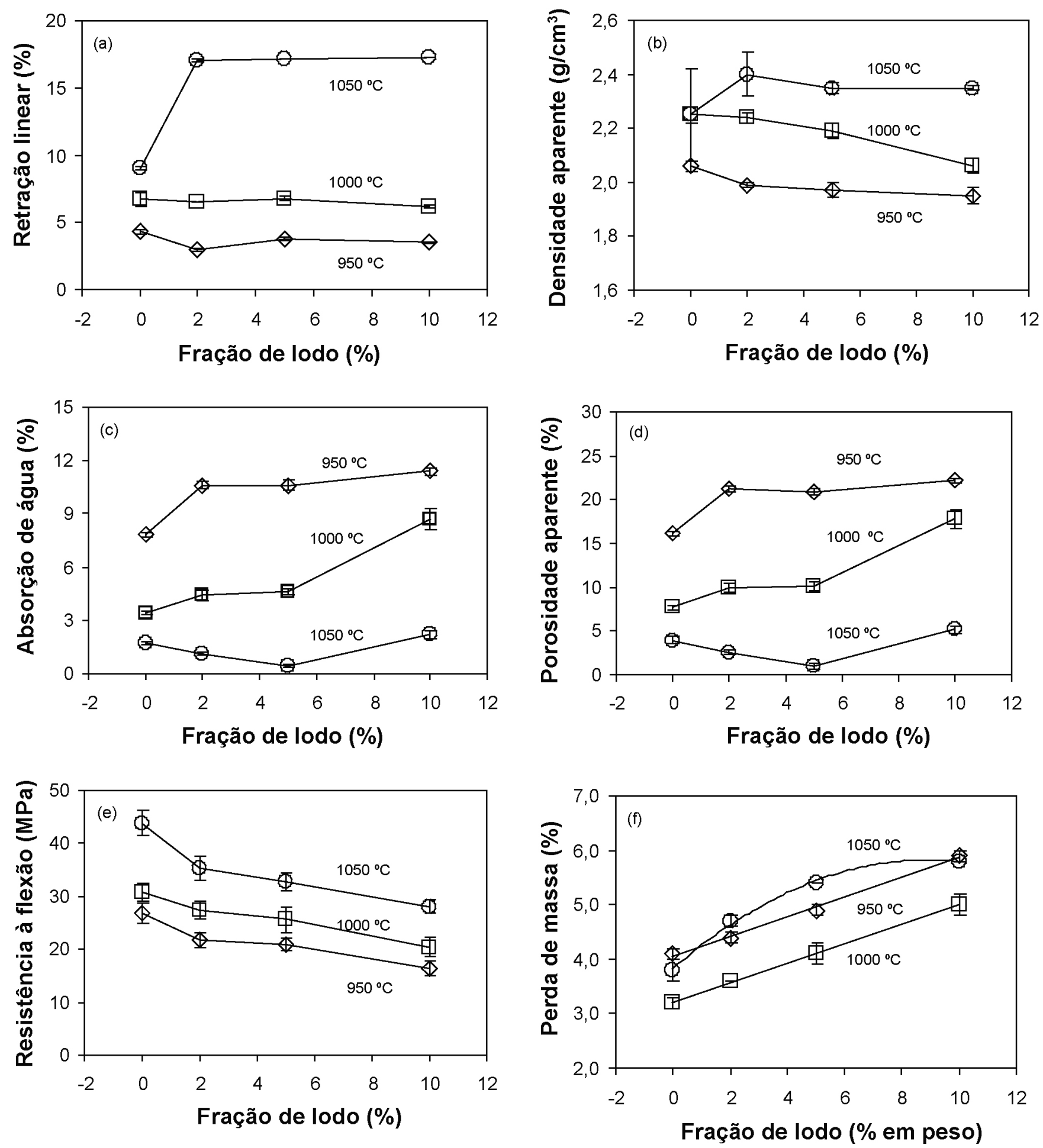

Figura 9: Resultados das caracterizações físicas das amostras sinterizadas entre 950 e $1050{ }^{\circ} \mathrm{C}$ em função da fração de lodo adicionada. [Figure 9: Results of physical properties of samples sintered between 950 and $1050^{\circ} \mathrm{C}$ as a function of sludge fraction.] 
sugere que acima de $1000{ }^{\circ} \mathrm{C}$ ocorreu ativação do processo de sinterização assistida por fase líquida [17, 18], que intensificou a densificação (Fig. 9b). Os principais componentes tanto da massa argilosa como do lodo foram $\mathrm{SiO}_{2}, \mathrm{Al}_{2} \mathrm{O}_{3} \mathrm{e} \mathrm{Fe}_{2} \mathrm{O}_{3}(\sim$ $90 \%$, Tabelas I e II). A Fig. 10 apresenta as "calhas eutéticas" do diagrama de fases deste sistema e as indicações das composições da massa argilosa, do lodo e da amostra com $10 \%$ de lodo, considerando apenas os teores normalizados de $\mathrm{SiO}_{2}, \mathrm{Al}_{2} \mathrm{O}_{3}$ e $\mathrm{Fe}_{2} \mathrm{O}_{3}$. O lodo tem composição em uma região refratária do sistema, em acordo com a estabilidade das partículas do lodo na calcinação a $1000{ }^{\circ} \mathrm{C}$ (Fig. 6). A argila, por sua vez, tem composição em uma região de baixa temperatura liquidus, próxima à composição eutética de menor temperatura de fusão (ou solidus) do sistema $(<1546$ ${ }^{\circ} \mathrm{C}$, Fig. 10). A adição do lodo à massa argilosa aproximou a composição da mistura para a composição eutética, diminuindo a refratariedade do material. Esta análise indica que a adição do lodo rico em $\mathrm{Fe}_{2} \mathrm{O}_{3}$ favoreceu a formação de fase líquida em menor temperatura, o que ativou o processo de sinterização assistida por fase líquida a $1050{ }^{\circ} \mathrm{C}$, resultando em rápida densificação do corpo (Fig. 9b). Esta temperatura foi significativamente menor do que a menor temperatura eutética do sistema $\mathrm{SiO}_{2}-\mathrm{Al}_{2} \mathrm{O}_{3}-\mathrm{Fe}_{2} \mathrm{O}_{3}\left(<1546{ }^{\circ} \mathrm{C}\right.$, Fig. 10), possivelmente devido à presença de impurezas $(\sim 10 \%)$ na argila e no lodo (Tabelas I e II).

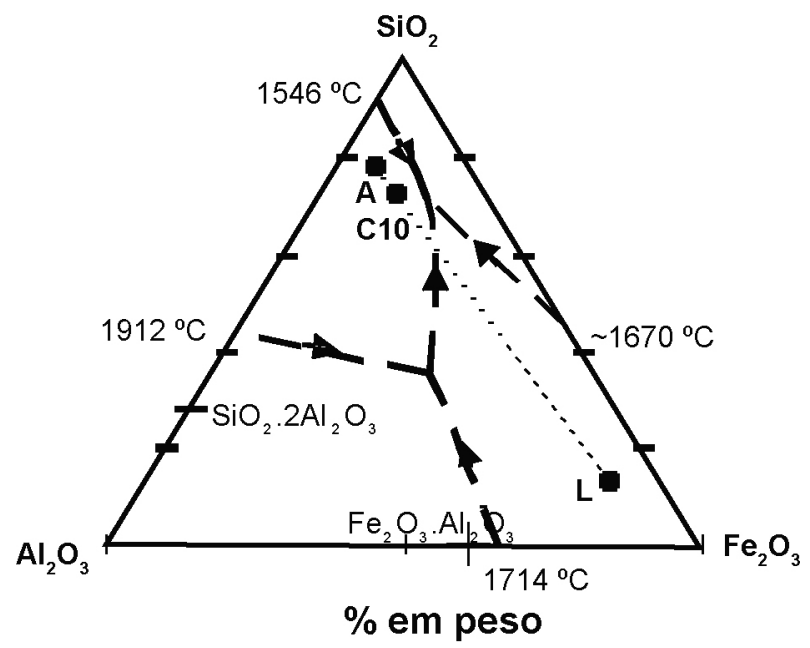

Figura 10: Sistema $\mathrm{SiO}_{2}-\mathrm{Al}_{2} \mathrm{O}_{3}-\mathrm{Fe}_{2} \mathrm{O}_{3}$ (baseado nas Figs. 87, 766, 2095 e 4373 de [19]). As composições da massa argilosa (A), do lodo (L) e da amostra com 10\% de lodo (C10) estão indicadas com o símbolo $(\bullet)$.

[Figure 10: $\mathrm{SiO}_{2}-\mathrm{Al}_{2} \mathrm{O}_{3}-\mathrm{Fe}_{2} \mathrm{O}_{3}$ system (based on Figs. 87, 766, 2095, and 4373 of [19]). The compositions of clay (A), sludge (L), and sample with $10 \%$ sludge (C10) are indicated with symbol (•).]

As amostras com lodo apresentaram valores de absorção de água maiores do que a amostra de controle (sem lodo), quando sinterizadas a 950 e $1000{ }^{\circ} \mathrm{C}$ (Fig. 9c). A adição de $2 \mathrm{e}$ $5 \%$ de lodo causou o aumento de $\sim 35 \%$ na absorção de água. A adição de $10 \%$ de lodo aumentou significativamente a absorção de água para valores de 11,4 e $8,7 \%$ quando sinterizadas a 950 e $1000{ }^{\circ} \mathrm{C}$, respectivamente, que correspondem a aumentos de
46 e 156\% em relação à amostra de controle (Fig. 9c). Logo, é recomendável a adição de até $\sim 5 \%$ do lodo na massa argilosa investigada para que não ocorra excessivo aumento da porosidade aparente (Fig. 9d) e, em conseqüência, absorção de água (Fig. 9c). A resistência à flexão tendeu a diminuir com o aumento da fração de lodo em todas as temperaturas de sinterização investigadas (Fig. 9e), enquanto a perda de massa teve comportamento oposto (Fig. 9f).

A Fig. 11 apresenta micrografias ópticas da superfície "como sinterizada" das amostras com e sem lodo. A superfície da amostra sem adição de lodo apresentou-se relativamente lisa, com poucos defeitos superficiais (Fig. 11a). A adição de lodo, entretanto, causou a formação de irregularidades superficiais associadas com as partículas maiores do lodo, cuja fração aumentou com o aumento da fração de lodo adicionada (Figs. $11 \mathrm{~b}$ a 11d). Em maior ampliação, observou-se que muitas partículas grandes do lodo estavam descoladas da matriz argilosa, formando microtrincas ao redor das mesmas (Fig. 12a). Estas microtrincas persistiram mesmo após sinterização a $1050{ }^{\circ} \mathrm{C}$, quando a matriz argilosa apresentou aspecto vitrificado (Fig. 12b). Uma possibilidade para a formação das microtrincas é que tenha ocorrido, durante o aquecimento na sinterização, retração mais rápida das partículas do lodo do que a matriz argilosa, ao se transformarem de composto amorfo (Fig. 4) em hematita (Fig. 5), causando o descolamento das partículas de lodo. Outra possibilidade é que durante o estágio de resfriamento, após a sinterização, a fraca adesão entre as partículas de lodo e a massa argilosa não suportou a tensão gerada na interface pela diferença de coeficiente de expansão térmica entre a partícula e a matriz, causando a ruptura da interface. As microtrincas associadas às partículas do lodo explicam, ao menos em parte, os maiores valores de absorção de água nas amostras com lodo (Fig. 9c).

A resistência à flexão apresentou tendência de rápida diminuição com a adição de $2 \%$ de lodo ( $20 \%$ de redução em relação à amostra de controle) e depois apresentou redução gradativa com o aumento da fração de lodo, nas três temperaturas de sinterização investigadas (Fig. 9e). Esta tendência de diminuição não pode ser explicada pela variação da retração linear (Fig. 9a) e porosidade aparente (Fig. 9d). Possivelmente, as microtrincas associadas às partículas do lodo (Fig. 12a) enfraqueceram as amostras preparadas com adição deste resíduo. A rápida diminuição da resistência com adição de apenas $2 \%$ do lodo mostra a severidade das partículas de lodo na limitação da tensão de ruptura da cerâmica, possivelmente associada a sua forma angular (Fig. 2). A resistência à flexão diminuiu com o aumento da fração de lodo devido ao aumento da fração de microtrincas associadas às partículas do lodo.

A resistência à flexão, $\sigma_{\mathrm{f}}$, de materiais cerâmicos está relacionada com o tamanho do defeito que origina a fratura, c, segundo a relação de Griffith-Irwin [20]:

$\sigma_{\mathrm{f}}=\frac{\mathrm{K}_{\mathrm{Ic}}}{\mathrm{Y} \sqrt{\mathrm{c}}}$

onde, $\mathrm{K}_{\mathrm{Ic}}$ é a tenacidade à fratura (constante do material) e $\mathrm{Y}$ é 
(a)

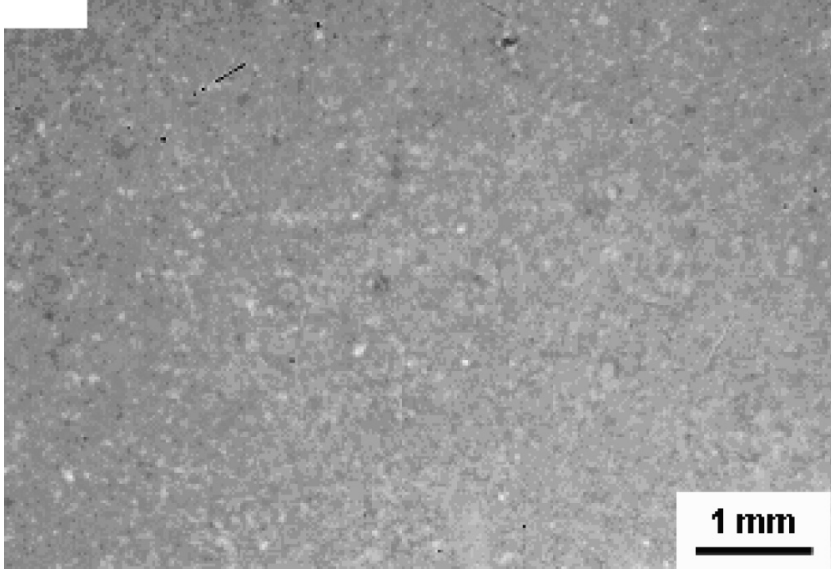

(c)

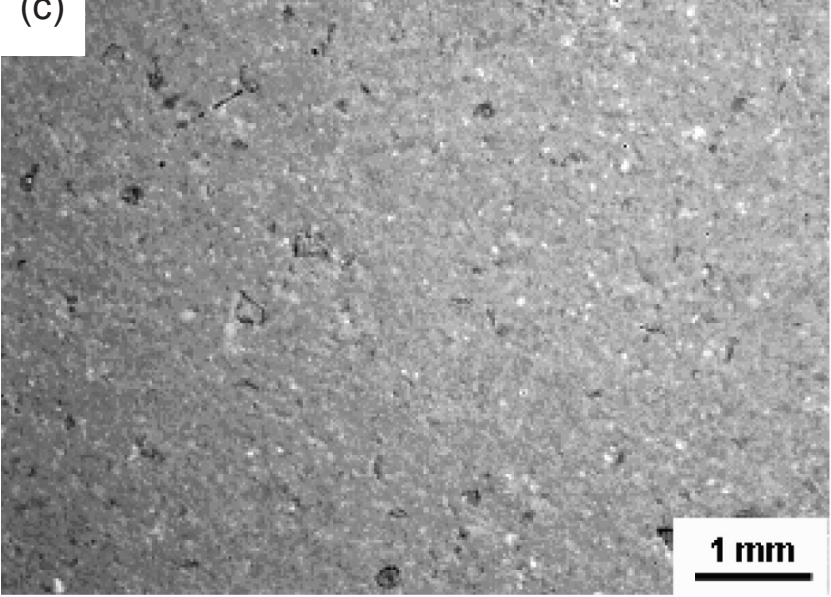

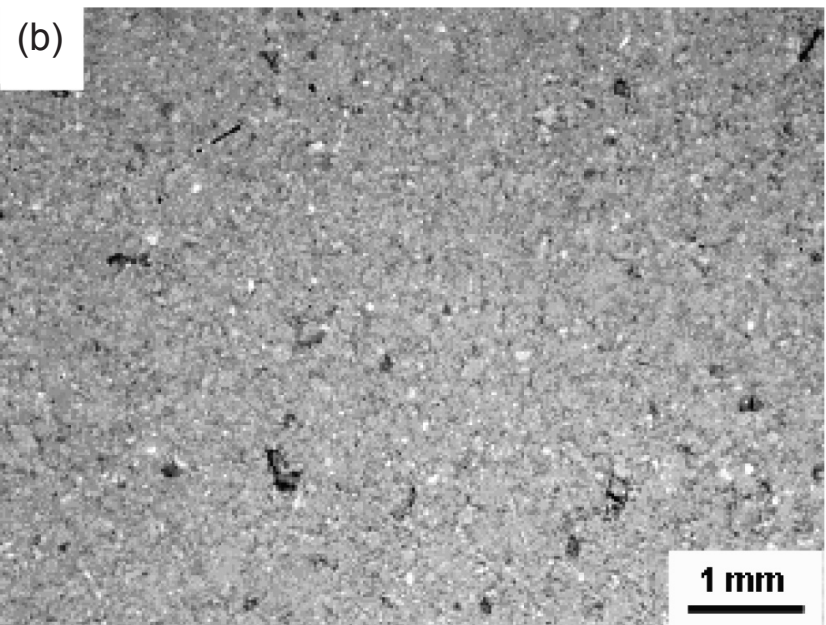

(d)

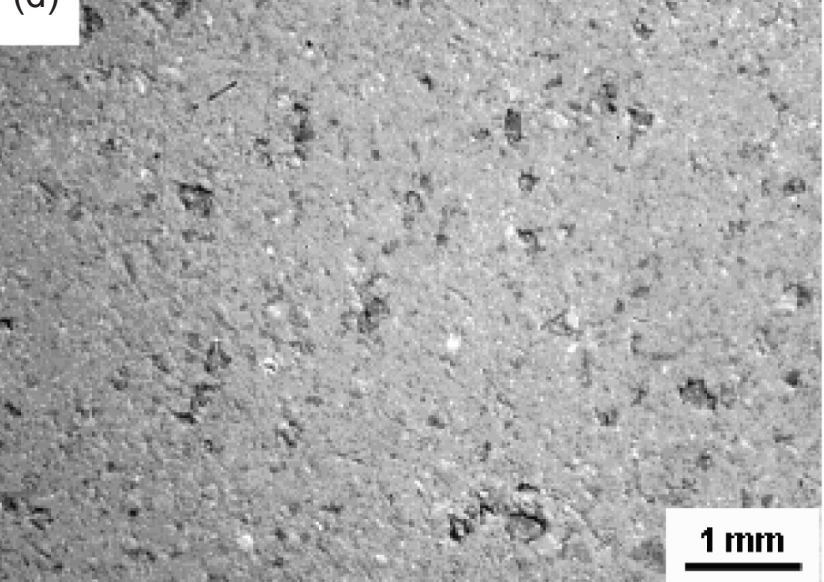

Figura 11: Micrografias ópticas da superfície "como sinterizada" das amostras sem lodo (a) e com $2 \%$ (b), $5 \%$ (c) e $10 \%$ (d) de lodo sinterizadas a $950{ }^{\circ} \mathrm{C}$.

[Figure 11: Optical micrographs of as-sintered surface of samples without sludge (a) and with 2\% (b), $5 \%$ (c), and 10\% (d) of sludge sintered at $\left.950^{\circ} \mathrm{C}.\right]$
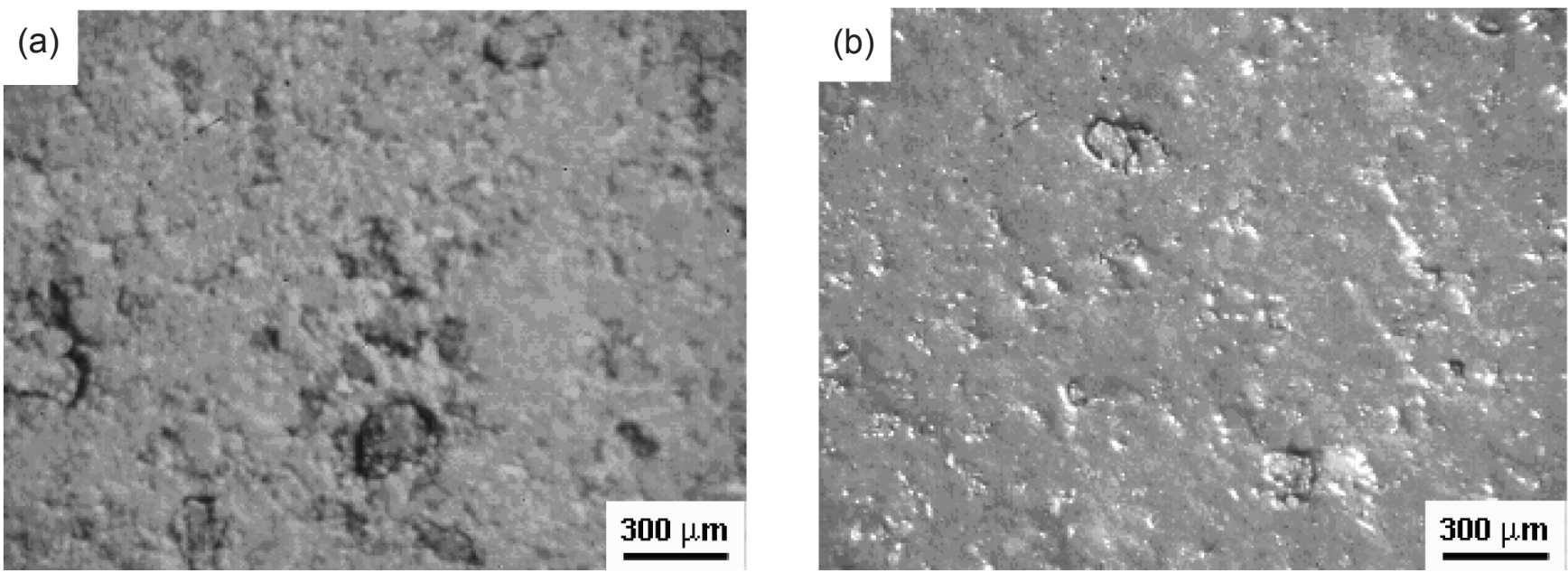

Figura 12: Micrografias ópticas da superfície "como sinterizada" das amostras: (a) com $2 \%$ de lodo sinterizada a $950{ }^{\circ} \mathrm{C}$; e (b) com $10 \%$ de lodo sinterizada a $1050^{\circ} \mathrm{C}$.

[Figure 12: Optical micrographs of as-sintered surface of samples: (a) with $2 \%$ sludge sintered at $950{ }^{\circ} \mathrm{C}$; and (b) with $10 \%$ sludge sintered at $1050^{\circ} \mathrm{C}$.] 
um fator geométrico relacionado à forma de carregamento, geometria, localização e dimensões do defeito limitador da resistência. Supondo um valor de $\mathrm{K}_{\mathrm{Ic}}$ de $0,5 \mathrm{MPa} \cdot \mathrm{m}^{1 / 2} \mathrm{e}$ valor de Y de 1,3 para trinca semi-elíptica superficial [21], o tamanho do defeito, c, estimado foi de $370 \mu \mathrm{m}$ para um valor de $\sigma_{\mathrm{f}}$ de $20 \mathrm{MPa}$ (este valor é próximo ao da amostra com $5 \%$ de lodo sinterizada a $950{ }^{\circ} \mathrm{C}$, Fig. 9e). O valor estimado do tamanho do defeito crítico foi próximo ao tamanho $\mathrm{D}_{90}$ das partículas do lodo $(334 \mu \mathrm{m}$, Fig. 1b), o que reforça que as microtrincas associadas às partículas do lodo (Fig. 12) limitaram a resistência à flexão nas amostras com lodo.

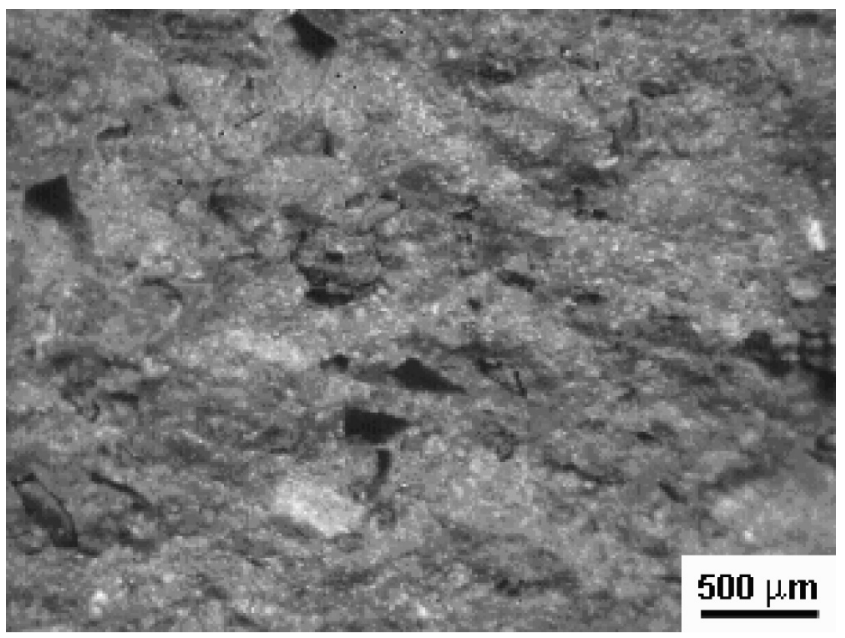

Figura 13: Imagem (EMO) de superfície de fratura das amostras com $5 \%$ de lodo bruto sinterizada a $1000{ }^{\circ} \mathrm{C}$.

[Figure 13: Image of fractured surface of the samples with $5 \%$ raw sludge sintered at $1000^{\circ} \mathrm{C}$.]

O aumento da resistência à flexão das amostras com lodo com o aumento da temperatura de sinterização parece ter sido influenciado, principalmente, pelo aumento da resistência mecânica da matriz argilosa, como indicam os resultados da amostra de controle (Fig. 9e). A Fig. 13 mostra imagem da superfície de fratura de uma amostra com lodo, onde se observam cavidades com formato angular, similar à forma das partículas grossas do lodo (Fig. 2). Também, observam-se partículas do lodo remanescentes nas superfícies de fratura, muitas com trincas no seu contorno, mostrando que a maioria das partículas estava solta dentro da cavidade formada pela fratura da interface partícula-matriz argilosa. Mecanicamente, as partículas rodeadas por trinca não suportam carregamento, o que as tornam equivalentes a poros. Assim, a resistência à flexão das amostras com lodo foi definida pela resistência da matriz argilosa, sendo que as partículas do lodo atuaram como vazios, que enfraqueceram a cerâmica.

A perda de massa (perda ao fogo) seguiu tendência linear com o aumento da fração de lodo quando a sinterização foi realizada a 950 e $1000{ }^{\circ} \mathrm{C}$, mas passou a parabólico a $1050{ }^{\circ} \mathrm{C}$, tendendo a um valor máximo de $\sim 6 \%$ (Fig. 9f). A perda de massa, entretanto, foi maior a
$950{ }^{\circ} \mathrm{C}$ do que a $1000{ }^{\circ} \mathrm{C}$, devido à maior perda de massa da matriz argilosa. Não foi possível determinar a razão deste comportamento, mas a maior retração do corpo sinterizado a $1000{ }^{\circ} \mathrm{C}$, em relação ao corpo sinterizado a $950{ }^{\circ} \mathrm{C}$ (Fig. 9a), pode ter dificultado a saída dos gases voláteis do interior do corpo, diminuindo a perda de massa.

\section{Corpos cerâmicos: efeito do beneficiamento do lodo}

Nesta série, foram investigados os efeitos do beneficiamento do lodo (calcinação a $1000{ }^{\circ} \mathrm{C}$ e moagem para tamanho inferior a $74 \mu \mathrm{m}$ ) nas características físicas e mecânicas das cerâmicas preparadas com $5 \%$ de lodo. $\mathrm{A}$ adição de lodo calcinado e moído, praticamente, não influenciou a retração linear e a resistência à flexão dos corpos prensados e secos a $110^{\circ} \mathrm{C}$, em relação à adição do lodo bruto (Fig. 14). A exceção foi a maior resistência à flexão observada na amostra com lodo calcinado, mas que ainda foi $22 \%$ menor do que a da amostra sem lodo. As diferenças nas características físico-químicas das superfícies dos pós têm sido correlacionadas com as variações das propriedades mecânicas $\left(\sigma_{\mathrm{f}} \mathrm{e} \mathrm{K}_{\mathrm{Ic}}\right)$ de corpos verdes (prensados) preparados com diferentes pós nanométricos de alumina [22]. Possivelmente, as interações na superfície do lodo calcinado com a massa argilosa foram diferentes do lodo bruto, uma vez que apresentaram estruturas cristalinas e compostos significativamente diferentes (Figs. 4 e 5), o que pode explicar o maior valor de resistência à flexão observado na amostra com lodo calcinado, em relação às demais amostras com lodo (Fig. 14).

A Fig. 15 apresenta os resultados das caracterizações físicas das amostras sinterizadas entre 950 e $1050{ }^{\circ} \mathrm{C}$ por 3 h. A adição de lodo calcinado ou moído pouco afetou a retração linear (Fig. 15a) e a densidade aparente (Fig.

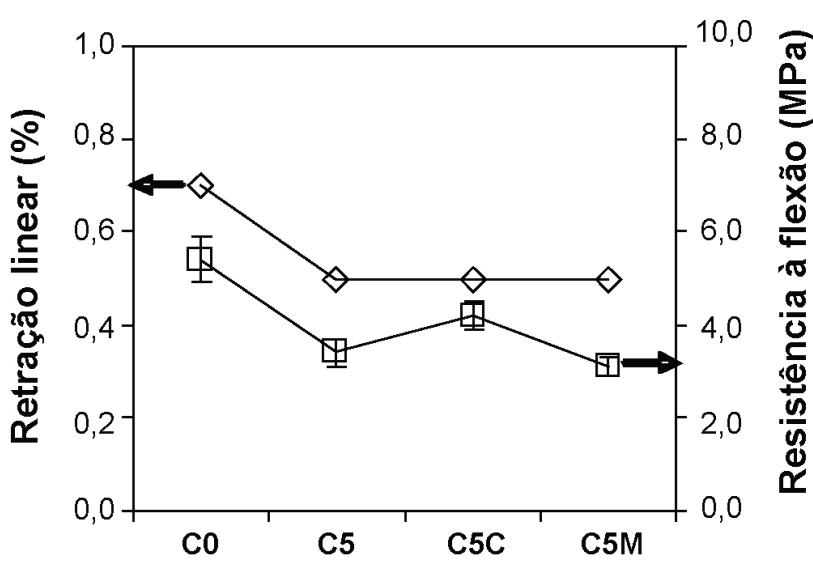

Figura 14: Retração linear e resistência à flexão dos corpos prensados e secos a $110{ }^{\circ} \mathrm{C}$ das amostras: $\mathrm{C} 0$, sem lodo; $\mathrm{C} 5$, com $5 \%$ de lodo bruto; C5C, com 5\% de lodo calcinado; e C5M, com $5 \%$ de lodo moído.

[Figure 14: Linear shrinkage and flexural strength of pressed bodies dried at $110^{\circ} \mathrm{C}$ of the samples: C0, without sludge; $\mathrm{C5}$, with $5 \%$ raw sludge; $C 5 C$, with $5 \%$ calcined sludge; and C5M, with 5\% milled sludge.] 
15b), em relação à amostra preparada com lodo bruto, com exceção da amostra com lodo moído sinterizada a $1000{ }^{\circ} \mathrm{C}$, que apresentou menor densidade aparente. A porosidade aparente não foi influenciada pelo beneficiamento do lodo nas temperaturas de sinterização de 950 e $1050{ }^{\circ} \mathrm{C}$ (Fig. 15d). $\mathrm{Na}$ temperatura de sinterização de $1000{ }^{\circ} \mathrm{C}$, entretanto, as amostras com lodo calcinado ou moído apresentaram elevados valores de porosidade aparente ( $15 \%$, Fig. $15 \mathrm{~d})$, o que resultou

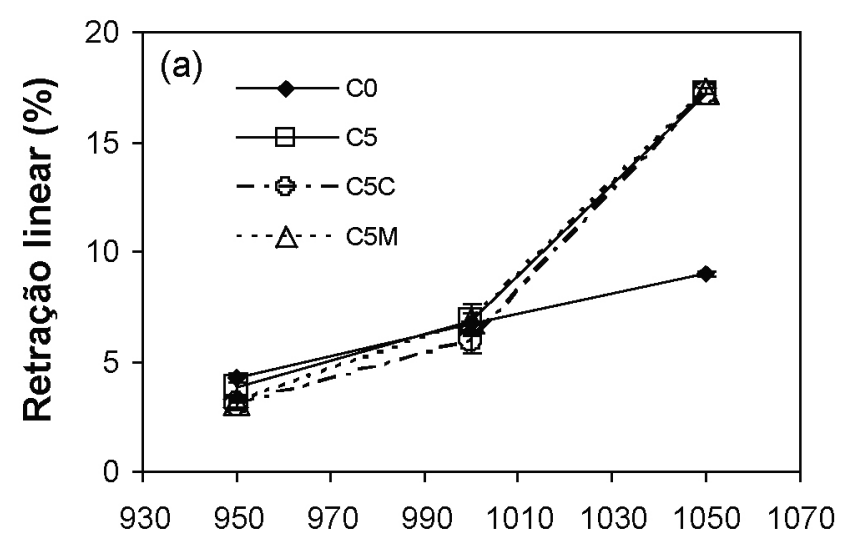

Temperatura de sinterização $\left({ }^{\circ} \mathrm{C}\right)$

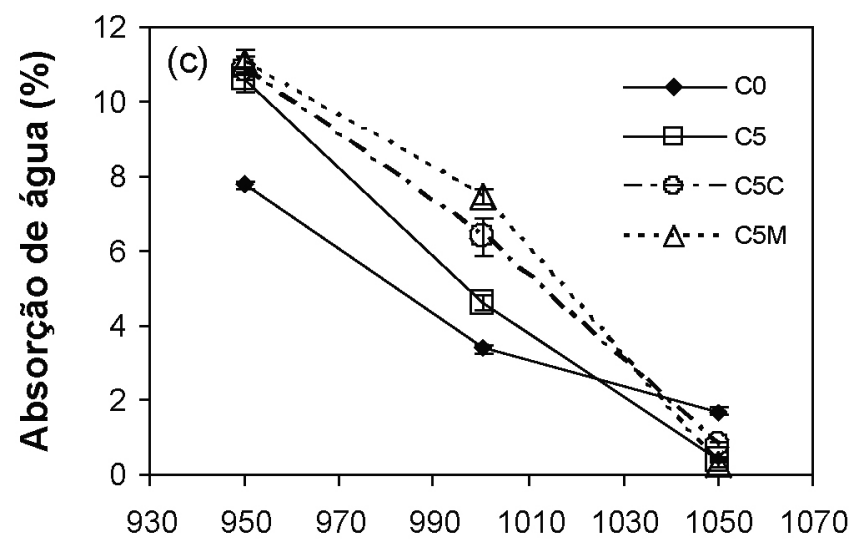

Temperatura de sinterização $\left({ }^{\circ} \mathrm{C}\right)$

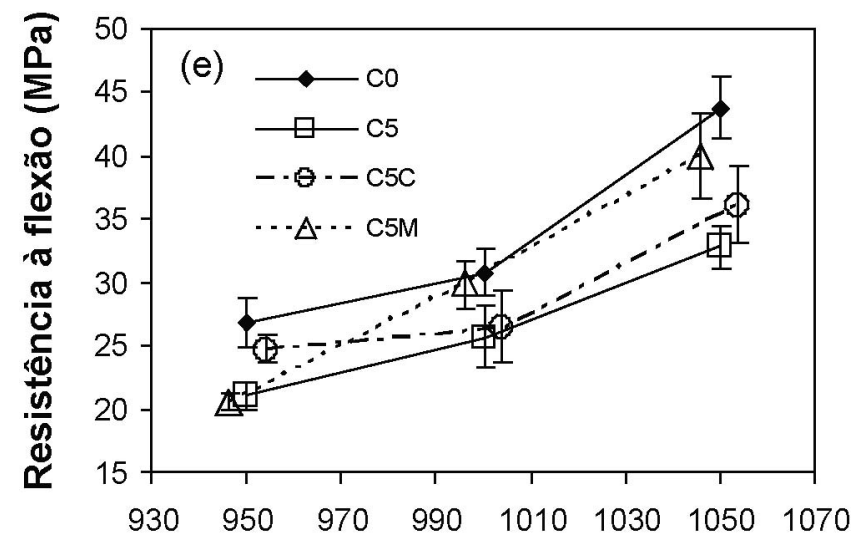

Temperatura de sinterização $\left({ }^{\circ} \mathrm{C}\right)$

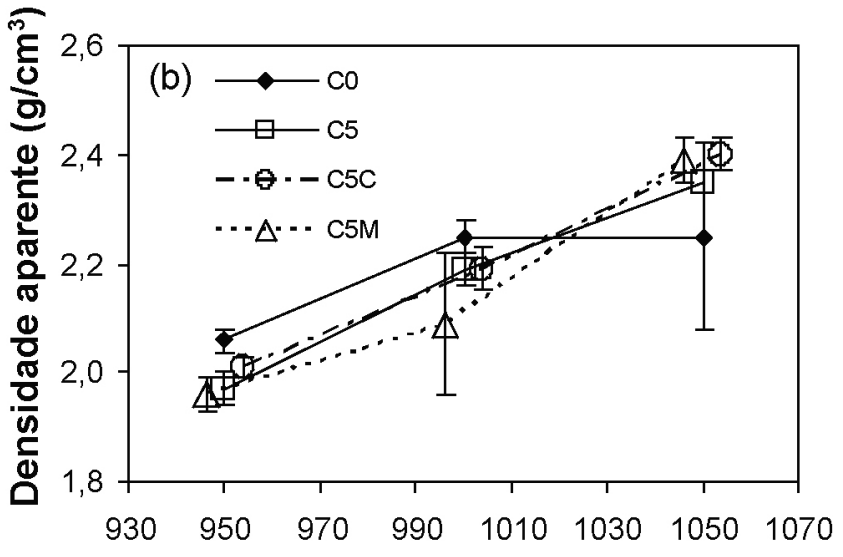

Temperatura de sinterização $\left({ }^{\circ} \mathrm{C}\right)$
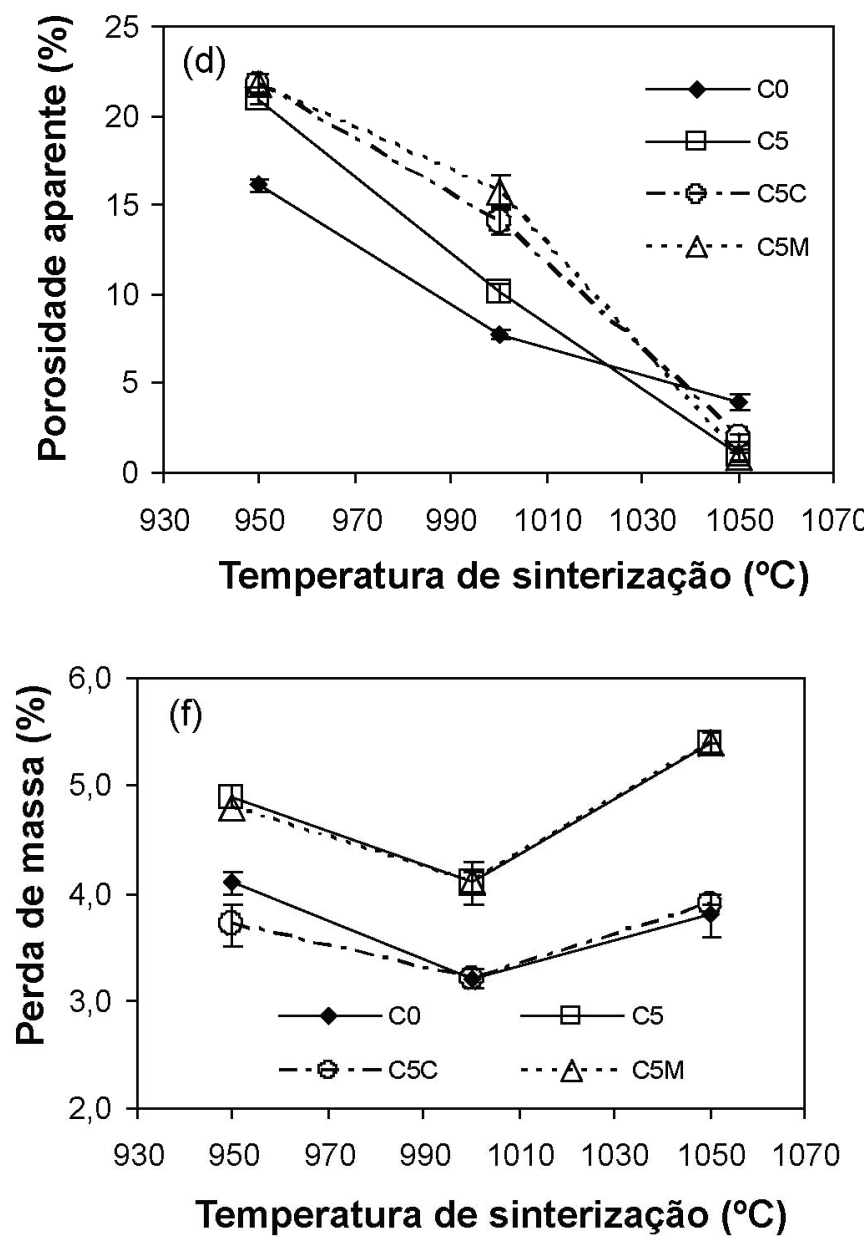

Figura 15: Resultados das caracterizações físicas das amostras sinterizadas entre 950 e $1050{ }^{\circ} \mathrm{C}$ das amostras: $\mathrm{C} 0$, sem lodo; $\mathrm{C} 5$, com $5 \%$ de lodo bruto; C5C, com 5\% de lodo calcinado; e C5M, com 5\% de lodo moído. Em (b) e (e), os valores das amostras C5C e C5M foram ligeiramente deslocados das temperaturas de sinterização para facilitar a visualização.

[Figure 15: Results of physical properties of the samples sintered between 950 and $1050^{\circ} \mathrm{C}$ of the samples: C0, without sludge; C5, with $5 \%$ raw sludge; $C 5 C$, with 5\% calcined sludge; and C5M, with 5\% milled sludge. In (b) and (e), the values of samples C5C and C5M were slightly shifted from the sintering temperature to make easy the view.] 
em aumento de cerca de $100 \%$ no valor de absorção de água em relação à amostra sem lodo (Fig. 15c). Não foi possível determinar o motivo do efeito deletério da adição do lodo beneficiado na absorção de água da cerâmica, mas, no caso do lodo moído, a fração de microtrincas geradas ao redor das partículas do lodo pode ter sido proporcional à área de superfície específica do pó, que foi maior no lodo moído.

Os resultados de resistência à flexão mostraram que os beneficiamentos do lodo resultaram em aumento da resistência em relação à amostra com lodo bruto (Fig. $15 \mathrm{e})$. Entre as amostras sinterizadas a $950{ }^{\circ} \mathrm{C}$, a adição de lodo calcinado resultou em resistência à flexão que mais se aproximou da amostra sem lodo. Já a 1000 e $1050{ }^{\circ} \mathrm{C}$, a adição de lodo moído resultou em valores que mais se aproximaram da amostra sem lodo. No caso da moagem, o efeito benéfico desta operação consistiu na diminuição do tamanho das partículas do lodo, reduzindo o tamanho do defeito limitador da resistência. Segundo a equação de Griffith-Irwin (Eq. A), a redução de $50 \%$ no tamanho do defeito pode levar a um aumento de $41 \%$ na resistência mecânica. No caso da amostra com lodo moído sinterizada a $1000{ }^{\circ} \mathrm{C}$, a resistência à flexão foi próxima à da amostra de controle, indicando que os defeitos associados às partículas do lodo apresentaram tamanhos próximos aos dos defeitos "naturais" da massa argilosa. A calcinação pode ter tido, além do efeito benéfico da retração das partículas durante o tratamento térmico, os efeitos de estabilização dimensional, química e de fases do lodo.

A Fig. 16 apresenta micrografias ópticas da superfície como sinterizada das amostras com lodo calcinado e moído. Comparando com a micrografia da amostra com $5 \%$ de lodo bruto (Fig. 11c), nota-se que a fração de defeitos superficiais associados às partículas grandes do lodo diminuiu significativamente tanto para o lodo calcinado (Fig. 16a) como moído (Fig. 16b), em concordância com a análise dos resultados anteriormente apresentados. Observouse, também, que as partículas maiores do lodo calcinado apresentaram microtrincas no seu contorno. A presença de cavidades vazias e microtrincas ao redor das partículas na superfície da fratura da amostra com lodo calcinado sinterizada a $950{ }^{\circ} \mathrm{C}$ (Fig. 17), similar à da amostra com lodo bruto (Fig. 13), não pode ser explicada pela retração das partículas durante o aquecimento, uma vez que elas foram dimensionalmente estabilizadas na calcinação a $1000^{\circ} \mathrm{C}$. Ao menos no caso do lodo calcinado, a microtrinca deve ter sido gerada durante o estágio de resfriamento na sinterização. Possivelmente, a tensão gerada na interface pela diferença de coeficiente de expansão térmica entre as partículas de hematita e a matriz argilosa causou a ruptura da interface.

A perda de massa na sinterização apresentou valores de perda de massa próximos aos da amostra sem lodo, enquanto o tamanho de partícula do lodo não teve efeito na perda de massa das amostras com lodo bruto e moído (Fig. 15f).

$\mathrm{O}$ beneficiamento do lodo por calcinação ou moagem foi eficiente em reduzir o efeito deletério das suas partículas na resistência à flexão, sem ter alterado significativamente as demais características físicas avaliadas, exceto em alguns
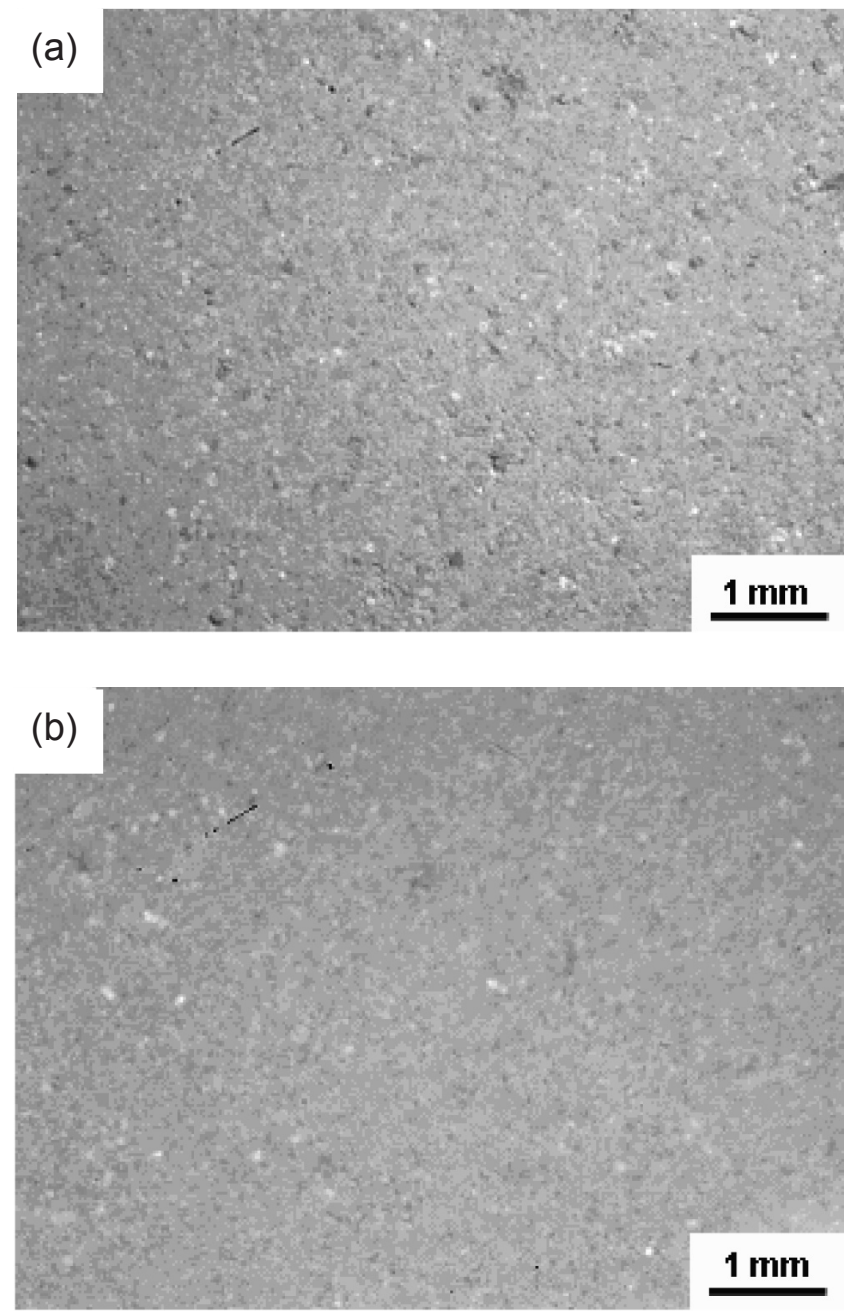

Figura 16: Micrografias ópticas da superfície "como sinterizada" das amostras com 5\% de lodo calcinado (a) e 5\% de lodo moído (b) sinterizadas a $950{ }^{\circ} \mathrm{C}$.

[Figure 16: Optical micrographs of as-sintered surface of the samples with 5\% calcined sludge (a) and 5\% milled sludge (b) sintered at $950^{\circ} \mathrm{C}$.]

casos em que teve efeito deletério de aumentar a absorção de água e a porosidade aparente (Figs. 15c e 15d). Os resultados sugerem que a realização conjunta de calcinação e moagem pode resultar em desempenho mecânico superior, o que pode propiciar o aumento da fração máxima de lodo a ser incorporada na massa argilosa.

A moagem é um processo mais recomendado do que a calcinação, por consumir menor energia. Assim, no caso da incorporação de resíduo particulado que não apresenta significativa interação com a matriz argilosa e forma defeitos que diminuem a resistência mecânica, como o lodo de ETA com alto teor de $\mathrm{Fe}_{2} \mathrm{O}_{3}$ deste trabalho e o resíduo borra de petróleo investigado por Souza e Holanda [14], a moagem do resíduo para tamanhos menores do que os defeitos limitadores da resistência da massa cerâmica é uma forma de diminuir o efeito negativo da formação de defeitos associados às partículas do resíduo, como microtrincas. 


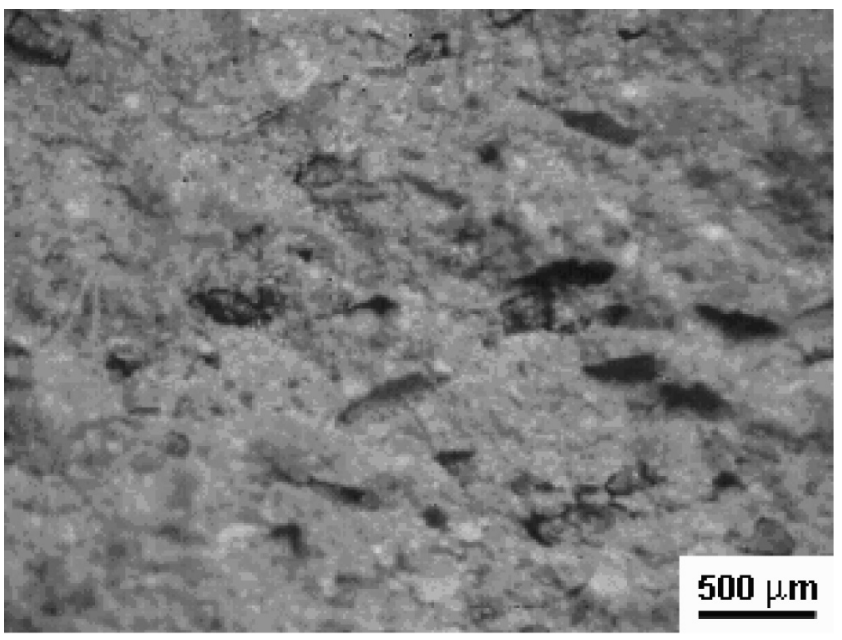

Figura 17: Imagem (EMO) de superfície de fratura da amostra com $5 \%$ de lodo calcinado sinterizada a $950{ }^{\circ} \mathrm{C}$.

[Figure 17: Image of fractured surface of the sample with 5\% calcined sludge sintered at $950^{\circ} \mathrm{C}$.]

\section{Comentários finais}

A adição do lodo de ETA com alto teor de $\mathrm{Fe}_{2} \mathrm{O}_{3}$ causou efeitos deletérios em diversas características físicas e mecânicas da massa cerâmica investigada. Diminuiu a resistência à flexão do corpo seco (Fig. 8) e do corpo sinterizado (Fig. 9e), aumentou a absorção de água (Fig. 9c) e a porosidade aparente (Fig. 9d), e diminuiu a temperatura máxima de sinterização para a não ocorrência de retração linear excessiva (Fig. 9a). Entre 2 e 5\% de lodo, as características físicas e mecânicas das cerâmicas foram próximas, mas a adição de $10 \%$ de lodo causou variação significativa das propriedades acima mencionadas. Em particular, a resistência à flexão do corpo sinterizado diminuiu $\sim 35$ a $40 \%$ em relação à massa argilosa (Fig. 9e). Estes resultados indicam que é recomendável a incorporação do lodo de ETA até um máximo de $\sim 5 \%$ de lodo na massa argilosa utilizada, para que as características físicas do corpo cerâmico não sejam fortemente degradadas. Esta fração, entretanto, pode ser aumentada, com o beneficiamento por calcinação e/ou moagem do lodo, o que diminui o efeito deletério das partículas do lodo na resistência mecânica (Fig. 15e).

Em termos dos limites indicados das propriedades físicas e mecânicas para potencial uso em cerâmica vermelha de Souza Santos [16], excetuando a super-queima (overfiring) a $1050{ }^{\circ} \mathrm{C}$, todas as amostras com lodo, incluindo a de $10 \%$, apresentaram resultados dentro dos limites indicados. A fração máxima de lodo de ETA que pode ser incorporada em uma cerâmica vermelha (e de qualquer resíduo que não apresente forte interação com a massa argilosa) depende fortemente das características da massa argilosa, i.e., da capacidade da matriz cerâmica em suportar os defeitos gerados pelo resíduo. Isto significa que, para uma dada adição de resíduo, a tenacidade à fratura, $\mathrm{K}_{\mathrm{Ic}}$, da matriz argilosa é que define a resistência mecânica da cerâmica. A fração máxima de adição do resíduo depende, também, como apresentado anteriormente, das características das partículas. Para uma dada massa cerâmica, as abordagens pelas quais se podem diminuir o efeito deletério das partículas do lodo ou de um resíduo inerte incluem estabilizar o material por meio de tratamento térmico (calcinação) e alterar a forma, tamanho e distribuição das partículas por meio de moagem.

\section{CONCLUSÕES}

O lodo de ETA analisado apresentou partículas grossas e angulares, elevado teor de ferro e predominância de composto com estrutura amorfa. O lodo calcinado a $1000^{\circ} \mathrm{C}$ transformou-se, principalmente, em hematita $\left(\mathrm{Fe}_{2} \mathrm{O}_{3}\right)$, com $18 \%$ de perda de massa, e as partículas mantiveram a forma original.

A adição do lodo em uma massa de cerâmica vermelha em frações de 2 a $10 \%$, em peso causou diminuição da resistência à flexão do corpo seco a $110{ }^{\circ} \mathrm{C}$, devido, principalmente, à redução da retração linear de secagem. As partículas de lodo interagiram pouco com a matriz argilosa até $1000{ }^{\circ} \mathrm{C}$. Acima desta temperatura, o lodo reagiu com a massa cerâmica e aumentou significativamente a retração linear. Até $1000{ }^{\circ} \mathrm{C}$, a incorporação do lodo pouco afetou a retração linear da cerâmica, mas aumentou a absorção de água e diminuiu a resistência à flexão. Os efeitos deletérios da incorporação do lodo foram causados pela formação de microtrincas ao redor das partículas. A forma angular das partículas parece explicar o rápido decréscimo da resistência à flexão com a adição de apenas $2 \%$ de lodo. A calcinação e a cominuição do lodo possibilitaram aumentar a resistência à flexão em relação à incorporação do lodo bruto, diminuindo a severidade das microtrincas.

\section{REFERÊNCIAS}

[1] G. E. Oliveira, J. N. F. Holanda, Cerâmica 50 (2004) 75. [2] I. S. S. dos Santos, L. M. Calarge, A. R. Scherer, C. S. Kazmierczak, C. G. S. Machado, S. Battisti, Anais do $43^{\circ}$ Congresso Brasileiro de Cerâmica, S. Paulo (1999) p. 22201.

[3] R. S. Santos, G. P. Souza, J. N. F. Holanda, Cerâmica 48 (2002) 115.

[4] V. T. Balaton, P. S. Gonçalves, L. M. Ferrer, Cerâmica Industrial 7, 6 (2002) 42.

[5] P. F. Fernandes, A. P. N. Oliveira, D. Hotza, Cerâmica Industrial 8, 2 (2003) 26.

[6] O. R. K. Montedo, G. M. Reitz, F. M. Bertan, R. Piccoli, D. Hotza, A. P. N. de Oliveira, Cerâmica Industrial 8, 5/6 (2003) 14.

[7] C.-H. Weng, D.-F. Lin, P.-C. Chiang, Adv. Environmental Res. 7 (2003) 679.

[8] Y. Wag, Condicionamento de Lodo de Estação de Tratamento de Água: Estudo de Caso, Diss. Mestrado, Escola Politécnica da Universidade de S. Paulo (1996) p. 50.

[9] M. A. P. Reali, Coordenação Programa de Pesquisa 
de Saneamento Básico, Noções Gerais de Tratamento e Disposição Final de Lodos de Estações de Tratamento de Água, PROSAB, Rio de Janeiro (1999) p. 21.

[10] M. T. Tsutiya, A. Y. Hirata, Anais do $21^{\circ}$ Congresso de Engenharia Sanitária e Ambiental, J. Pessoa (2000) p. 1.

[11] M. V. V. Ramires, I. S. S. dos Santos, C. S. Kazmierczak, Anais do $49^{\circ}$ Congresso Brasileiro de Cerâmica, S. Pedro (2005) p. 1.

[12] M. V. V. Ramires, I. S. S. dos Santos, C. S. Kazmierczak, A. H. C. Silva, A. P. Kern, S. A. Camargo, Anais do $45^{\circ}$ Congresso Brasileiro de Cerâmica, Florianópolis (2001) p. 0401301.

[13] S. Cosin, V. F. J. Kozievitch, D. T. Tavares, M. M. G. R. Vianna, S. M. Toffoli, P. S. Santos, F. R. Valenzuela-Díaz, Anais do $46^{\circ}$ Congresso Brasileiro de Cerâmica, S. Paulo (2002) p. 599.

[14] G. P. Souza, J. N. F. Holanda, Cerâmica 49 (2003) 128.

[15] A. C. de Camargo, J. C. S. Portela, H. N. Yoshimura,
Cerâmica Industrial 10, 2 (2005) 39.

[16] P. S. Santos, Ciência e Tecnologia de Argilas, 2a Ed., Edgard Blücher, S. Paulo (1992) p. 175.

[17] A. L. Molisani, H. Goldenstein, H. N. Yoshimura, Boletim Técnico da Escola Politécnica da USP, BT/ PMT/0601 (2006) p. 1.

[18] A. L. Molisani, H. N. Yoshimura, H. Goldenstein, K. Watari, J. Eur. Ceram. Soc. 26, 15 (2006) 3431.

[19] E. M. Levin, C. R. Robbins, H. F. McMurdie, Phase Diagrams for Ceramists, The Am. Ceram. Soc., Ohio, EUA (1979).

[20] H. N. Yoshimura, A. L. Molisani, N. E. Narita, J. L. A. Manholetti, J. M. Cavenaghi, Mater. Sci. Forum 530 (2006) 408.

[21] T. Fett, D. Munz, O. Rosenfelder, T. Thiemeier, J. Mater. Sci. Lett. 16 (1997) 1255.

[22] A. B. K. Njiwa, E. Aulbach, J. Rödel, A. Neubrand, J. Am. Ceram. Soc. 89, 8 (2006) 2641.

(Rec. 20/07/2007, Rev. 31/08/2007, Ac. 14/09/2007) 